\title{
Comparative Study on the Reservoir Characteristics and Development Technologies of Two Typical Karst Weathering- Crust Carbonate Gas Reservoirs in China
}

\author{
Haijun Yan, ${ }^{1}$ Ailin Jia, ${ }^{1}$ Fankun Meng $\mathbb{D}^{2},{ }^{2}$ Qinyu Xia, ${ }^{1}$ Wei Xu, ${ }^{3}$ Qingfu Feng, ${ }^{1}$ Wenjun Luo, ${ }^{3}$ \\ Xinyu Li, ${ }^{1}$ Xun $\mathrm{Zhu}^{3}$ and Yicheng Liu ${ }^{3}$ \\ ${ }^{1}$ Research Institute of Petroleum Exploration \& Development, Beijing 100083, China \\ ${ }^{2}$ School of Petroleum Engineering, Yangtze University, Wuhan 430100, China \\ ${ }^{3}$ Research Institute of Petroleum Exploration \& Development, Southwest Oil and Gas Field Company, Chengdu 610051, China
}

Correspondence should be addressed to Fankun Meng; mengfk09021021@163.com

Received 11 December 2020; Accepted 24 May 2021; Published 10 June 2021

Academic Editor: Basim Abu-Jdayil

Copyright (c) 2021 Haijun Yan et al. This is an open access article distributed under the Creative Commons Attribution License, which permits unrestricted use, distribution, and reproduction in any medium, provided the original work is properly cited.

\begin{abstract}
Carbonate reservoirs are the main reservoir types in China, which occupy the large ratio of reserves and production at present. The high-efficiency development of carbonate reservoirs is of great significance to assure the stability of national energy supply. The Lower Paleozoic reservoir in Jingbian gas field and the Sinian reservoir in Anyue gas field are two typical carbonate gas reservoirs, and their successful development experiences can provide significant references for other similar carbonate gas reservoirs. For Jingbian gas field, it is a lithological-stratigraphic reservoir developed in a westward monocline and multiple rows of nose-fold structures, and is a stable craton basin with simple palaeognomy distribution and stable connectivity, which has complex gas-water distribution. However, for Anyue gas field, it is a lithological-structural reservoir with multiple tectonic high points and multiple fault systems, and is biological dune beach facies under extensional setting with highly differentiated inside of the block in palaeognomy characteristics, which has limited connectivity and tectonic side water is in a local area. The difference of gas reservoir characteristics leads to the diverse development strategies. For these two gas reservoirs, although there are some similar aspects, such as the screen of enrichment areas, the application of irregular well pattern and reservoir stimulation techniques, the criteria of enrichment areas, the well types, and the means of reservoir stimulation are absolutely different. In addition, due to the differences of control reserves and production capacity for these two kinds of reservoirs, the mode of stable production is also different. The effective development of Jingbian gas field can give some references to the future exploitation on the Sinian gas reservoir. Firstly, the sedimentary characteristics should be studied comprehensively. Secondly, the distribution pattern and distribution characteristics of the palaeognomy should be found and determined. Thirdly, the distribution of fracture system in the reservoir should be depicted finely. Finally, dynamic monitoring on the production performance should be strengthened, and the management for this gas field should be improved further. The findings of this study can help for better understanding of the Karst weathering-crust carbonate gas reservoir formation characteristics and the optimal development technologies that should be taken in practice.
\end{abstract}

\section{Introduction}

Carbonate rock is an important type of oil and gas reservoirs. $45 \%$ of global natural gas recoverable reserves and $60 \%$ of production are attributed to carbonate rock reservoirs. Due to its physicochemical properties, carbonate rock reservoirs account- ing for more than $80 \%$ of proven gas initially found in place (GIIP) are found with origins that are related to karst processes. Karst reservoirs refer to reservoirs associated with karstification, whose coming-into-being is controlled by unconformity types, slope setting, and faulting. Karst weathering-crust reservoirs are the most important type of karst reservoirs. The oil 
and gas exploration and development practice have proven that many petroliferous basins in the world are developed with carbonate rock paleoweathering-crust hydrocarbon-bearing reservoirs. According to statistics, $20 \%-30 \%$ of the global oil and gas are related to the formation unconformity, specifically related to the paleoweathering crust $[1,2]$. In terms of the exploration and development of oil and gas fields in China, the carbonate rock paleoweathering-crust and paleokarst reservoirs associated with unconformity are commonly developed and moreover play a very important role. Karst reservoirs are one of the critical reservoir types in China's marine petroliferous basins, and are widely distributed in multiple hydrocarbonbearing formation series of the Ordos Basin, Sichuan Basin, Tarim Basin, and Bohai Bay Basin in China [3-6]. Among those, the Lower Paleozoic gas reservoir in the Jingbian gas field, Ordos Basin and the Sinian gas reservoir in the Anyue gas field, Sichuan Basin are the most monolithic karst weathering-crust carbonate rock gas reservoirs in China, with the largest proven GIIP. The Jingbian gas field is one of the first large-scale karst weathering-crust carbonate rock gas fields in China that has been discovered and successfully put into development $[7,8]$. It is one of the main gas fields in Changqing gas area. As for the Sinian gas reservoir in the Anyue gas field, Sichuan Basin, it is a monolithic weathering-crust carbonate rock gas reservoir with the oldest payzone, the most complex gas reservoir characteristics, and largest GIIP in China $[9,10]$. Currently, it is reported that GIIP of this gas reservoir amounts to trillions of cubic meters, and the gas field is building its production capacity. Since its discovery 30 years ago, the Jingbian gas field has actively carried out various testing and research on challenges involved in the production establishment and production stimulation. The understanding of the gas reservoirs has gradually become clear, a series of supporting technologies have been developed, and abundant development experience has accumulated, which greatly supports the initial production building and long-term stable production of the Jingbian gas field. So far, the Jingbian gas field has maintained an annual production of 5.5 billion cubic meters for 14 years in a row, and the cumulative gas production has exceeded more than 85 billion cubic meters, which results in tremendous economic and social benefits. Because the two types of gas reservoirs both belong to the karst weathering-crust carbonate rock gas reservoir, it is of great guiding significance to compare and analyze the similarities and differences between the gas reservoir characteristics and development technology strategies and learn from the successful development experience of the Jingbian gas field, for expanding the exploration area of the Sinian gas reservoir in the Sichuan Basin, and development appraisal and rapid production establishment of the Gaomo area.

For the review on the formation characteristics and the development technologies for carbonate gas reservoirs, on the one hand, some researchers summarize the comprehensive studies on identification, characterization, and modelling for different fault/fracture systems, and highlight the different rock texture aspects for some typical carbonate reservoirs $[11,12]$. On the other hand, many investigators present some EOR methods that have been used in the exploitation of carbonate reservoirs, such as Water-Alternating-Gas (WAG), polymer flooding, and smart water flooding, and review the mechanisms for these methods for different reservoir conditions [13-16]. However, there are no reviews on the formation features and development strategies simultaneously, and more studies either focus on the formation geology or development technology. Therefore, in this paper, in terms of two typical carbonate gas reservoirs in China, we do not only study the formation characteristics for these two reservoirs, such as structure, sedimentation, and pore types, but we also review the development strategies and technologies in field practice, which can be seen as the primary novelty compared with previous researches. To some extent, the studies in this paper can support the efficient development on the similar carbonate reservoirs in the world.

The structure of this paper is organized as follow: first, the overview of these two carbonate gas reservoirs is presented; second, the development history for these two reservoirs is illustrated; third, the formation characteristics of gas reservoirs are compared and analyzed comprehensively, which include reservoir structure, sedimentation features, formation connectivity, and distribution of gas-water zone; fourth, the development strategies and technologies that have been taken for these two reservoirs are analyzed and studied in detail, which contain the selection of enrichment areas, the utilization of well patterns and stimulation technologies, and the methods for reservoir production stabilization. The fifth part is the inspirations for the development of similar carbonate gas reservoirs from the comparative analysis on these two reservoirs, and finally the conclusions and summaries can be obtained. Furthermore, to show the skeleton of this article more clearly, the general sketch of this paper is shown in Figure 1.

\section{Overview of Two Gas Reservoirs}

2.1. Lower Paleozoic Gas Reservoirs in the Jingbian Gas Field. The Jingbian gas field is one of the birthplaces and main gas fields of the natural gas business in the Changqing oil and gas region. It is also the world's largest world-class monolithic low-permeability, low-abundance, and low-production gas field discovered in the late 1980s, following the Sichuan gas field [17, 18]. The Jingbian gas field is located in the central part of the Shanbei slope of the Ordos Basin and the Jingbian-Hengshan area on the northeast side of the central paleouplift. With the strike along the north-northeast direction, it has a length of about $240 \mathrm{~km}$, a width of about $130 \mathrm{~km}$, and an area of 3.12 $\times 10^{4} \mathrm{~km}^{2}$. It is a large-scale weathering-crust complex gas field with low permeability, low abundance, and low yield, associated with the Ordovician marine carbonate rock (Figure 2).

2.2. Sinian Gas Reservoirs in the Anyue Gas Field. The Sichuan Basin is the birthplace of China's natural gas industry, with history of natural gas extraction for more than a thousand years, and has 27 sets of gas-bearing strata. The potential for natural gas exploration and development is tremendous. The Anyue ultra-large gas field in the Sichuan Basin is the oldest and largest-in-reserve monolithic marine carbonate rock gas field in China, of which the discovery has tremendously boosted the exploration of deep oil and 


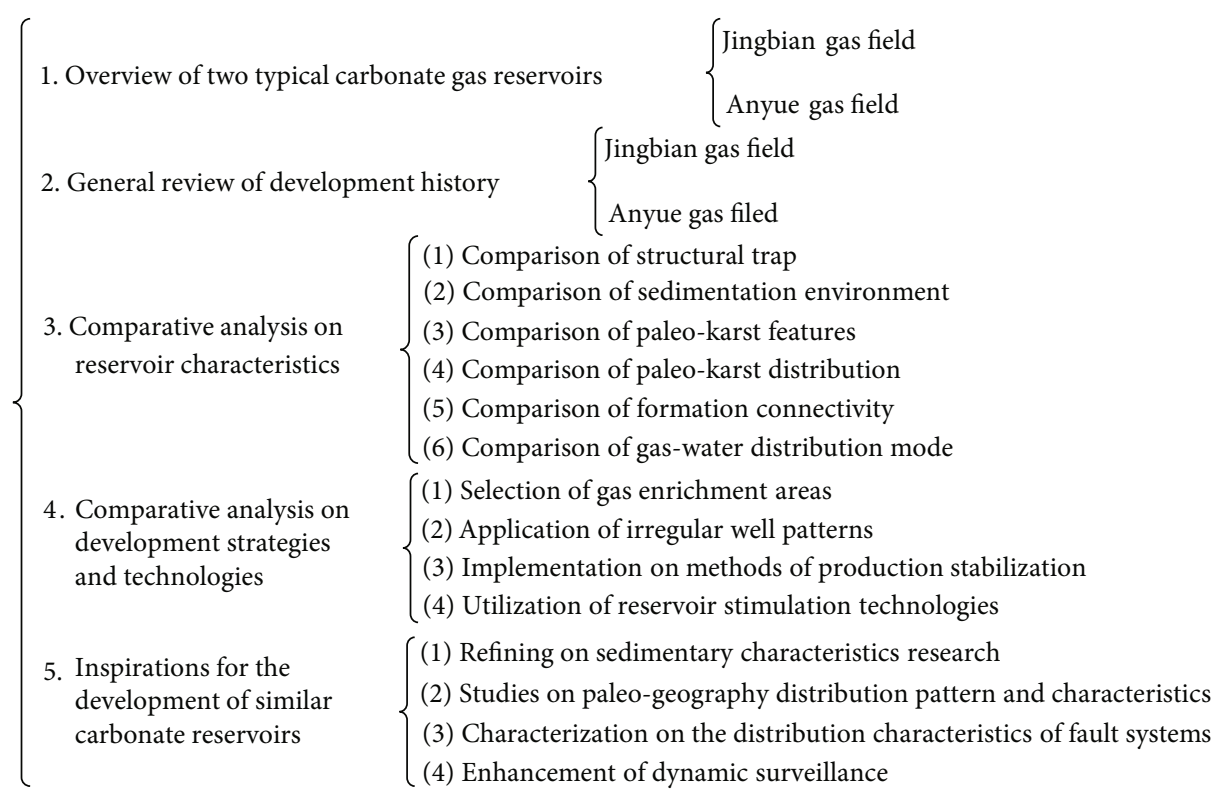

Figure 1: General sketch of this article.

gas in the Sichuan Basin [19-25]. The Gaoshi-1 well is the discovery well of the Sinian gas reservoir in the Anyue gas field, which is located in the higher part of the Gaoshiti structure of the Leshan-Longnvsi paleouplift in the Sichuan Basin, and the well completion is at the pre-Sinian system (Figure 3). During the drilling process, four gas detection anomalies, one gas intrusion event, and one loss-of-circulation event were observed in the Deng-4 Member of the Dengying Formation. In the meantime, the mud and wireline logging data have revealed the presence of the karst dolomite reservoir in the Dengying Formation. The Gaoshi-1 well obtained high-productionrate industrial streams from the Dengying Formation, which marks a major discovery in the exploration of the Sinian gas reservoir in the Anyue gas field.

The basic information of the Lower Paleozoic gas reservoir in the Jingbian gas field and the Sinian gas reservoir in the Gaomo area are shown in Table 1, which includes geological characteristics, formation and fluid properties, and development schemes.

\section{Comparative Analysis on the Development History}

3.1. Lower Paleozoic Gas Reservoirs of the Jingbian Gas Field in the Ordos Basin. The Jingbian gas field began with the pilot development test in 1991 and has been through four development stages:

3.1.1. Comprehensive Evaluation and Pilot Development (1991-1996). In this stage, the seismic survey grid was refined to minutely examine the lateral variation of the gas reservoir; evaluation wells were drilled to study regularity behind high production and gas accumulation, and to optimize the favorable areas for development; various test approaches and multiple methods were adopted to predict and evaluate the reasonable production capacity per individual well; technical testing such as deep-penetration acidizing tests was carried out to improve the productivity of low-production wells. The accomplishment of the six-year work mainly includes important tasks such as setting up of the Jingbian gas field development project, development of the surface engineering construction technical plan, and determination of the production scale prior to 2000. Moreover, awareness of complexity of the Jingbian gas field has been learned from 10 evaluation wells, and the development concept of "loosening drawdown pressures at the initial stage to stimulate production per well" was proposed, which laid foundation for coming-into-being of the production scale reaching $55 \times 10^{8} \mathrm{~m}^{3}$ per year.

3.1.2. Production Testing and Appraisal Based on Prospecting Wells (1997-1998). Tremendous efforts have been made to build an annual natural gas production capacity of $12 \times 10^{8} \mathrm{~m}^{3}$, with the average daily proration of a single well equal to $7.0 \times 10^{4} \mathrm{~m}^{3}$ , through production testing in prospecting wells. On July 1, 1997 and September 30, 1997, the Jingbian gas field accomplished the goals of supplying gas to Xi'an and Beijing, respectively, and the construction of a framework project for an annual output of $30 \times 10^{8} \mathrm{~m}^{3}$ of natural gas has been successfully completed. Meanwhile, through large-scale long-term production testing in exploratory wells combined with geological comprehensive research, seismic lateral prediction, interwell connectivity analysis and studies on characteristics of gas well production performance, the stable production capacity of the gas well was further identified. It is demonstrated that the reservoir range with effective connectivity is the basis for the stable production of gas wells, while the high degrees of how the reservoir is naturally fractured is the guarantee of high production. The optimized well placement, engineering scheme optimization design, and production stimulation technology were 


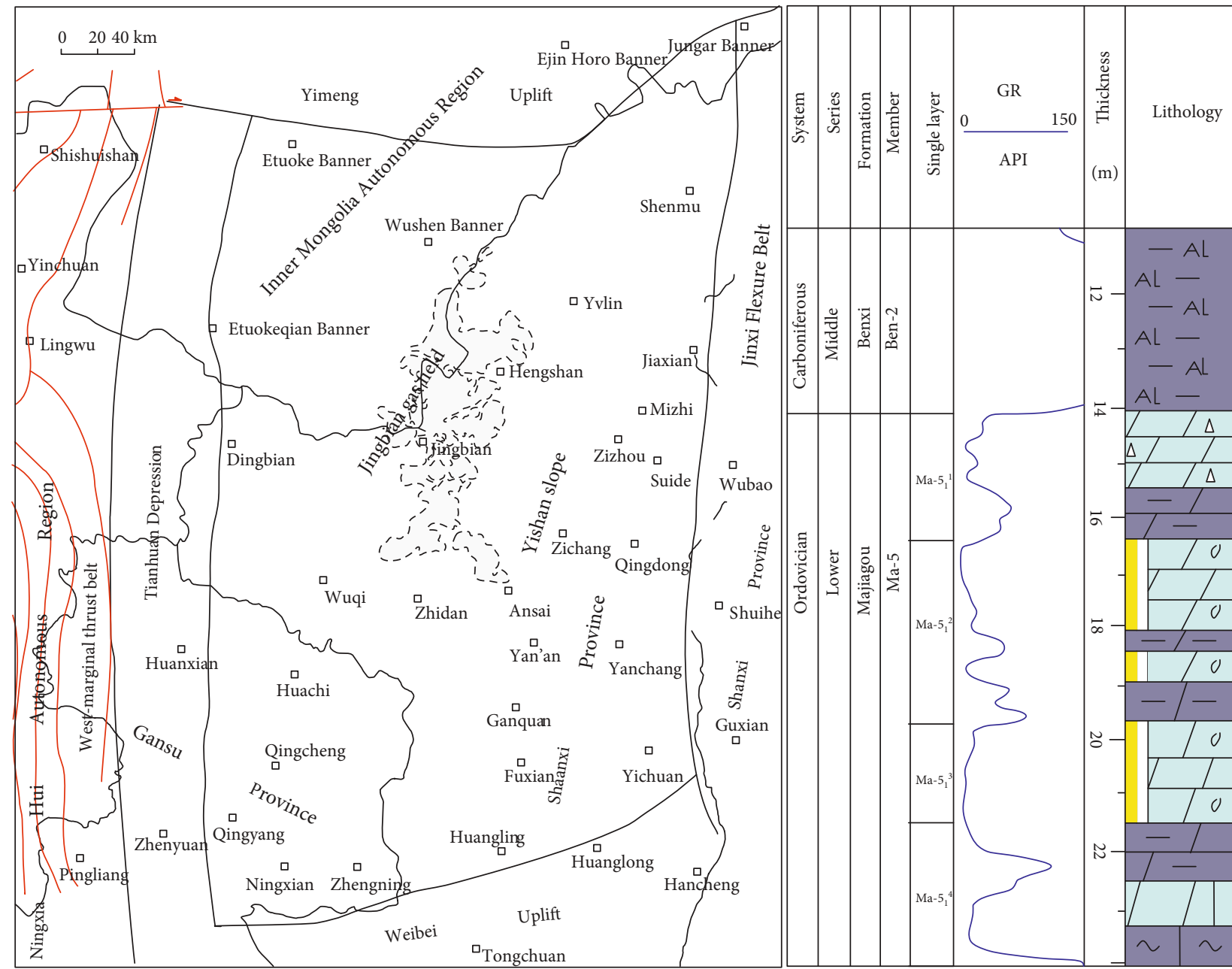

$$
\begin{aligned}
& \text { Structural unit boundary } \\
& \text { Fault } \\
& \text { Province boundary } \\
& \text { Range of Jingbian gas field }
\end{aligned}
$$

Breccia dolomite

Euddy dolotime

Dissolved-pore dolomite

堅 Tufa

Bauxitic mudstone

Figure 2: Structural characteristics of the Ordos Basin and location of the Jingbian gas field and stratigraphic column of the Lower Paleozoic reservoirs.

developed, which provide scientific and effective technical basis for the efficient development of the Jingbian gas field.

3.1.3. Large-Scale Development Stage (1999-2003). After six years of comprehensive evaluation and two years of prospecting-well production, the understanding of the Lower Paleozoic gas reservoir in Jingbian was further deepened, and various technologies became increasingly mature. In 1999, the gas field stepped into the large-scale development, and by the end of 2003, 339 wells in total have been drilled, among which 276 were development wells and 93 were prospecting wells. The producing geological reserves were 2695 $\times 10^{8} \mathrm{~m}^{3}$, with a production capacity of $55 \times 10^{8} \mathrm{~m}^{3} / \mathrm{a}$. Through years of technical research, the main development technology of the Jingbian gas field has been developed, including the reservoir comprehensive evaluation technology, seismic lateral reservoir distribution prediction technology, well placement optimization technology, gas well productivity evaluation technology, gas field development optimization design technology, gas production technology and, ground gathering and transportation technology.

3.1.4. Stable Production Stage (2004-Present). In 2004, the annual gas production of the Lower Paleozoic gas reservoir in the Jingbian gas field reached $55.1 \times 10^{8} \mathrm{~m}^{3}$. Since 2004 , the annual gas production has remained at about $50 \times 10^{8}-$ $55 \times 10^{8} \mathrm{~m}^{3}$, achieving the goal of long-term stable gas supply. Over the years, the well pattern infilling and adjustment, 


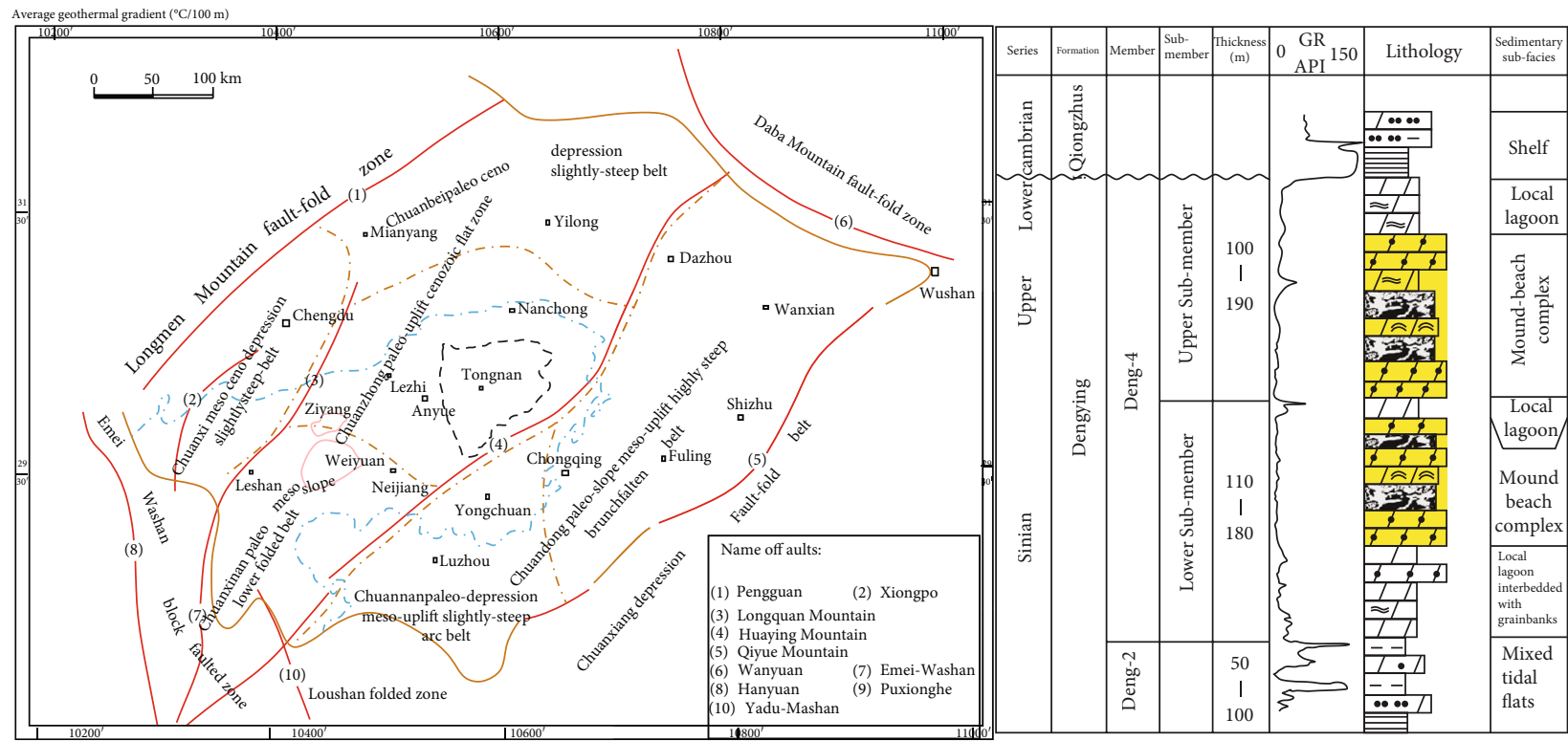

\begin{tabular}{|c|c|c|c|}
\hline$(2)$ & Basement rift & 豆 & Shale \\
\hline r & Boundary of Chuanzhong paleo-uplift & E- & Mudstone \\
\hline 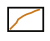 & Basin boundary & 满望 & Micritic limestone \\
\hline 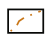 & Structural division boundary & 覧 & Laminar algal micritic dolomite \\
\hline E & Seismic survey zone boundary & 筒 & Algal stromatolite dolomite \\
\hline ك & Gas field boundary & 臣 & Sand clastic dolomite \\
\hline & Range of favorable gas-bearing areas in Gaomo & 욜 & Clot dolomite \\
\hline 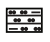 & Muddy siltstone & 圔 & Sandy dolomite \\
\hline 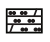 & Dolomitic siltstone & & Reservoir \\
\hline
\end{tabular}

Figure 3: Structure partition of the Sichuan Basin, location of the Anyue gas field, and stratigraphic column of the Sinian gas reservoir.

horizontal well development testing, pressure-charging recovery test, dewatering gas recovery and optimization of gas well working schemes, etc., have been carried out to form a series of low-permeability gas field production stabilization technologies with the Changqing characteristics. These include the well infilling adjustment based on fine reservoir description, horizontal well development technology to improve the singlewell production and producing degrees of low-quality reserves, pressure-charging recovery testing for enhanced gas recovery, refined gas reservoir management with the core of subdivision of development units, and gas reservoir dynamic surveillance involving fluids, pressures, production rates and corrosion monitoring.

3.2. Sinian Gas Reservoir in the Sichuan Basin. Beginning with the single-well production testing of Well Gaoshi-1 in 2012, the development of the Sinian gas reservoir of the Anyue gas field has gone through three stages.

3.2.1. Early Evaluation Stage (2012-2013). In view of the old and complex nature of the gas reservoir complex, strong heterogeneity, and large differences in gas well productivity, this stage was mainly to make full use of exploration results, and conduct formation testing, well testing, production testing, and data acquisition through the single-well produc- tion testing in Well Gaoshi-1, with objectives of preliminarily identifying gas reservoir geological characteristics. It is indicated that on the basis of reasonable production rates, gas wells are able to maintain a certain stable production capacity and achieve certain cumulative gas production. The resultant data have supported reporting of the three levels of reserves of the Sinian gas reservoir.

3.2.2. Development Evaluation Stage (2014-2016). In terms of the difficulty in cost-effective development of the gas reservoir and lack of effective key development technologies and practices, this stage focused on the placement of development evaluation wells and the development seismic surveys, production testing of the Gaoshiti and Moxi blocks, and the development of pilot testing zones, to deepen the understanding of gas reservoir characteristics, optimize the main development practice, accurately evaluate the gas well productivity and producible reserves, and complete the determination of the gas field development plan. On the basis of twophased production testing and a pilot testing zone, multiple rounds of gas reservoir description and practice testing were carried out, and the production-building block selection was optimized. The development well placement pattern and the production stimulation and reservoir reconstruction practices were continuously improved, and the goal of eliminating 
TABLe 1: Basic information of the Lower Paleozoic gas reservoir in the Jingbian gas field and the Sinian gas reservoir in Gaomo area.

\begin{tabular}{|c|c|c|}
\hline \multirow[b]{2}{*}{ Parameters } & \multicolumn{2}{|c|}{ Gas reservoir } \\
\hline & $\begin{array}{l}\text { Lower Paleozoic reservoir in the } \\
\text { Jingbian gas field }\end{array}$ & Sinian reservoir in the Anyue gas field \\
\hline Geographical location & Across Shanxi and Inner Mongolia & $\begin{array}{c}\text { Suining and Ziyang in Sichuan and Tongnan } \\
\text { in Chongqing }\end{array}$ \\
\hline Basin & Ordos Basin & Sichuan Basin \\
\hline Position for geological structures & Shanbei slope & Leshan-Longnvsi paleouplift \\
\hline Time of discovery & 1989 & 2010 \\
\hline Burial depth (m) & $300 \sim 3765$ & $4953 \sim 5535$ \\
\hline Target formation & Ordovician $\mathrm{Ma}-5_{1}$ & Sinian Deng-4 and Deng-2 \\
\hline Reservoir rock type & $\begin{array}{l}\text { Dolomite reservoir with dissolved } \\
\text { pores and vugs }\end{array}$ & Fractured-vuggy dolomite reservoir \\
\hline Gas reservoir type & $\begin{array}{l}\text { Composite stratigraphic-lithologic } \\
\text { trap }\end{array}$ & Composite stratigraphic-lithologic trap \\
\hline Cumulative gas-bearing layer average thickness (m) & 8.4 & 63 \\
\hline Average porosity (\%) & 5.47 & 3.3 \\
\hline Average permeability $\left(10^{-3} \mu \mathrm{m}^{2}\right)$ & 2.63 & 0.5 \\
\hline Gas-bearing area $\left(\mathrm{km}^{2}\right)$ & 9640 & 1085 \\
\hline Proven GIIP $\left(10^{8} \mathrm{~m}^{3}\right)$ & 5477 & 4084 \\
\hline Reserve abundance $\left(10^{8} \mathrm{~m}^{3} / \mathrm{km}^{2}\right)$ & 0.5682 & 3.12 \\
\hline Quantity of completed wells & 736 & 67 \\
\hline Average daily gas production per well $\left(10^{4} \mathrm{~m}^{3)}\right.$ & 3.26 & 17.3 \\
\hline Relative density of natural gas & $0.59 \sim 0.63$ & $0.59 \sim 0.64$ \\
\hline Average $\mathrm{CH}_{4}$ content $(\%)$ & 93.42 & 91.98 \\
\hline Average $\mathrm{CO}_{2}$ content $(\%)$ & 5.12 & 5.77 \\
\hline Average $\mathrm{H}_{2}$ Scontent $\left(/ \mathrm{m}^{3}\right)$ & 1489.57 & $1.24 \%$ \\
\hline Formation water type & $\mathrm{CaCl}_{2}$-type & $\mathrm{CaCl}_{2}$-type \\
\hline Average formation pressure $(\mathrm{MPa})$ & 30.24 & 59.65 \\
\hline Average formation pressure coefficient & 0.91 & 1.13 \\
\hline Average temperature $\left({ }^{\circ} \mathrm{C}\right)$ & 105.85 & 153.55 \\
\hline Average geothermal gradient $\left({ }^{\circ} \mathrm{C} / 100 \mathrm{~m}\right)$ & 3.05 & 2.6 \\
\hline
\end{tabular}

Type-III wells in the prospecting well was achieved. At this stage, the development plan is completed with high quality, and five major technologies have come into being, including the karst reservoir description technology, development favorable zone evaluation and optimization technology, development well target optimization technology, precise managedpressure drilling technology, and finely staged acid fracturing technology. At the same time, the single-well output was greatly improved, with the open flow capacity increasing from $75.05 \times 10^{4} \mathrm{~m}^{3 /} \mathrm{d}$ to $133.85 \times 10^{4} \mathrm{~m}^{3} / \mathrm{d}$ (by 1.78 times). The proportion of Type-I wells grew from $28.81 \%$ to $75 \%$, and Type-III wells were completely eliminated.

3.2.3. Production Capacity Building Stage (2017-2019). At present, the gas reservoir development is in the production capacity building stage. By producing from the proven reserves of $1600 \times 10^{8} \mathrm{~m}^{3}$, with irregular well patterns featuring main development well types of a combination of the deviated well + horizontal well, the production scale of 36 $\times 10^{8} \mathrm{~m}^{3} / \mathrm{a}$ is achieved. Because the various supporting technologies are relatively mature, the current work on capacity building is progressing smoothly.

\section{Comparative Analysis on Gas Reservoir Characteristics}

The Sinian gas reservoir in the Anyue gas field and the Lower Paleozoic gas reservoir in the Jingbian gas field are both karsttype weathering-crust carbonate rick gas reservoirs, and yet there are some differences in gas reservoir characteristics.

4.1. The Sinian Gas Reservoir in the Anyue Gas Field is Characterized by a Lithologic-Structural Trap Gas Reservoir with Multiple Structural High Points and Multiple Fault Systems, While the Jingbian Lower Paleozoic Gas Reservoir is a Lithologic-Stratigraphic Trap that Features a WestwardDipping Monocline and Multirowed Nose-Fold Structure. The top of the Sinian system in the Anyue gas field presents a large slowly dipping anticline structure, and the northeast-easttrending nose-like upheaval on the setting of the LeshanLongnvsi paleouplift, with multiple rows and high points. In this area, there are three nearly east-west-trending, northwest-trending, and northeast-trending normal faults, while the northwest trending is dominant, and most of them disappear above in the Cambrian formation and fade away in the 
Deng-2 Member below. On the other hand, due to the development of the rift trough, the lithologic pinch-out is found in the Deng-4 Member of the western part of the gas reservoir. In summary, the Sinian gas reservoir in the Anyue gas field is found as a lithologic-structural trap gas reservoir with multiple structural high points and multiple fault systems.

The Ordos Basin during Paleozoic was a stable craton basin, with the tectonic movement dominated by vertical rise-and-fall. The greatest feature of the basin is the development of a giant monoclinic structure dipping toward the west, namely the Shanbei slope. The slope structure is relatively stable and hardly seen with large regional faults. The Jingbian gas field is located in the north-central part of the Shanbei slope. It generally extends along the north-south direction, and there are no obvious structural traps, with only a few small folds, presenting dominant northeast and minor northwest trending. This series of nose folds are arranged in an echelon form, and nose folds in the northern and central areas are large, while those in the southern area is small. On the other hand, the gas traps have inconsiderable relationship with the structure, and are affected by the groove cutting action. Thus, the gas reservoirs are characterized by lithologic-stratigraphic traps. To sum up, the Lower Paleozoic gas reservoir in the Jingbian gas field is a lithologic-stratigraphic trap gas reservoir on the basis of a west-trending monocline.

4.2. The Sinian Gas Reservoir in the Anyue Gas Field Represents Sedimentation of the Platform Mound-Beach Facies under a Tensile Background, Which is Different from Deposition of the Tidal Flat Facies in Jingbian in the Case of a Stable Craton Basin. From the sedimentary period of the Sinian Dengying Formation to the Early Cambrian, the Upper Yangtze area has remained in a tensile environment for a long time, and the Sichuan Basin was characterized by the craton inner rift basin. The direct response to the Sinian tensile effects of the Sichuan Basin is the formation of the Deyang-Anyue inside-platform rift. Influenced by the formation and evolution of the rifting, the Sinian formation of the Sichuan Basin has a structural pattern of alternating convex and concave $[26,27]$. In the Deng- 1 and Deng- 2 periods, it is characterized by the paleogeographic background of "one upheaval and four sags"; due to the continuous tensile faulting of the Deyang-Anyue inside-platform rift as well as the penetration into the Changqing rift, the Sichuan Basin was divided into two parts, and evolved from the "one upheaval and four sags" into the "two upheaval and four sags," with respect to paleogeographic pattern $[28,29]$. The Deng-1 and Deng-3 Members are in the transgressive system tract, and meanwhile the Deng-2 and Deng-4 Members are of the highstand system tract. The effective reservoir is mainly developed in the Deng- 2 and Deng-4 Members. Controlled by the Anyue-Deyang rift trough, the Gaomo area is developed with open platform facies deposition. The high-energy mound-beach complex is found at the edge of the platform, while the low-energy mound-beach complex is developed inside the platform. Owing to paleoenvironment, paleostructure, paleowater depth, and paleoclimate characteristics, the development of mound and beach bodies in the vertical direction presented as evolving from being isolated to later- ally overlain and then to vertically overlain, from top to bottom. From the platform boundary to the interior of the platform, the degree of development of mound and beach bodies reduces, and the continuity and connectivity of mound and beach bodies deteriorate.

The Ordos Basin is a multicycle composite superimposed craton basin, which belongs to the substructural unit of the North China Platform. Its tectonic and sedimentary evolution is controlled by the Xingmeng trough on the north and the Qinqi trough in the southwest [30-32]. For the Ordos Basin, the inner is relatively stable internally, while the peripheral area is quite active [33]. In the early Ordovician, the north and south of the basin were controlled by the Xingmeng trough and the Qinqi Trough. The east and west were dominated by the remaining Helan aulacogen, and the central part was developed with an apparent positive tectonic unit, namely the "L"-shaped central paleouplift. Accordingly, the western and southern parts of the basin and the SuideYanchuan area in the eastern part are found with altitudinal differentiation, and the structural pattern of "upheaval in the west and sag in the east" was formed in the basin. The Majiagou Formation is mainly developed on the Yishan slope on the northeast part of the "L"-shaped central paleouplift. The Majiagou Formation can be divided into three gasbearing combinations: the upper combination includes the Ma- $5_{1}-\mathrm{Ma}-5_{4}$ submember, the middle combination includes the $\mathrm{Ma} 5_{5}-\mathrm{Ma}-5_{10}$ submember, and the lower combination includes formations from the Ma-4 Member to the Ma-1 Member. The lithology analysis shows that the Majiagou Formation has obvious cycles in the vertical direction, indicating that its sedimentation is affected by the oscillating relative sea level changes of different periods. The sedimentary environment of the Ma-5 Member in the Ordovician Majiagou Formation is an evaporative tidal flat environment with salinized and shallow water as well as frequent exposure. Its sedimentary facies has a slow width, a near-north-south trending, a stable lateral distribution, and a variable vertical facies sequence. A large amount of gypsum-salt nodules formed in the sediments of the supratidal zone, and the dispersed gypsum-salt crystals formed on the intertidal zone; these are the substance conditions for coming-into-being of the main storage space of the Ma-5 Member, which thereby laid a solid foundation for the paleokarst process and the formation and development of the dissolution pores and vugs.

The comparative analysis of the sedimentary environment demonstrates that the reservoir deposition of the Sinian gas reservoir in the Anyue gas field presents a sedimentary environment controlled by the rift trough. From bottom to the top, and from the platform edge to the platform interior, the scale, thickness, lithology, continuity, and connectivity of the mound and beach bodies are seen with certain variation regularity. Although the Lower Paleozoic gas reservoir in the Jingbian gas field is controlled by sedimentation cycles of different levels and different periods in the vertical direction, with resultant large lithology changes greatly, the lithological distribution in the lateral direction is much more stable than that in the Anyue gas field. The comparability of the Paleozoic gas reservoir across the whole area is far higher than that of the Dengying Formation in the Anyue gas field. 
4.3. The Paleokarst of the Top Sinian Formation of the Sichuan Basin is Characterized by "Three Upheavals and Two Sags," Which is Different from the Relatively Simple Paleokarst Landform Environment in the Ordos Basin Presenting "High in Central Part, While Low in the Eastern and Western Parts, and Steep in the West While Placid in the East." The Sichuan Basin is a NE-trending rhombic superimposed basin developed on the pre-Sinian metamorphic basement of the stable Yangtze craton (Figure 3). From the Nanhua period to Sinian, a largescale Nanhua rift valley was developed in the Upper Yangtze area. In the Sinian, the regional continental rifting ended and the evolutionary stage of the craton basin came. The multicycle tectonic movement results in the development of the multiperiod unconformity interfaces in the Sichuan Basin. Influenced by the Tongwan Phase-III tectonic movement, the Dengying Formation of the Anyue gas field is developed with two karst weathering-crust reservoirs of the Deng-2 and Deng-4 Members in the Dengying Formation. The results of previous studies on restoration of karst paleogeography across the entire Sichuan Basin Sinian System show that the top paleokarsts of the Sichuan Basin are characterized by "three upheavals and two sags" [34], and from west to east occur karst highlands, karst slopes, and karst basins, respectively. Controlled by the tensile rift trough, the karst slopes are seen with alternating karst lowlands and karst platforms.

The Ordos Basin is a complex craton basin with multiple tectonic regimes, multiple evolutionary stages, multiple sedimentary systems, and multi-overlain prototype basins. In different stages of geological development, complex tectonic deformations were generated due to different geodynamic backgrounds and tectonic stress field characteristics. After the Ordovician sedimentation, the sedimentary discontinuities of the Silurian and Devonian systems in the basin amounted to $1.3 \times 10^{12} \mathrm{a}$, which played a decisive role in the development of the Ordovician weathering-crust karst reservoir. The paleogeography of weathering rock under karst effects presents the characteristics of inheriting development, and still maintains the paleogeographic features of "high in central while low in east and west, and steep in west while placid in east." The eastern slope of the central paleouplift belongs to the karst slope area, in view of the paleogeography, with concentrated water streams and active runoff, which creates favorable conditions for the development of weathering-crust karst reservoirs.

The paleogeographical characteristics of the top of the Dengying Formation of the Sichuan Basin and the Ordovician in the Ordos Basin are quite different. The paleogeography of the Sinian karst weathering crust shows the characteristics of "three upheavals and two sags," and the distribution of karst paleogeography is relatively complicated. However, the karst paleogeography of the Ordovician weathering crust in the Ordos Basin is relatively simple. The entire basin is affected by the central paleouplift, which leads to the karst paleogeography featuring "high in central while low in west and east, and steep in west while placid in east."

4.4. The Paleogeographical Features of the Gaoshiti and Moxi Blocks in the Sichuan Basin Present Considerable Differences, Which is Different from the Relatively Monolithic Distribution of the Paleogeography in the Main Area of Jingbian. The res- toration results of karst paleogeography in the Gaoshiti-Moxi area indicate the development pattern of "two grooves and three blocks." The two geological troughs, namely Moxi 119 and Gaoshi 108, divide Gaoshiti-Moxi into three blocks: Gaoshiti, Moxi, and Gaoshitinan. In a macroscopic view, the Gaoshiti-Moxi area presents a sequence of paleogeographic distribution from east to west of the karst platform, karst slope, and karst lowland, and various secondary microgeographic units are developed inside the karst platform [35-37]. On the other hand, the distribution differences of the microgeographic units in the Gaoshiti and Moxi areas are also obvious. The Gaoshiti area is seen with a steep slope, while the Moxi area is dominated by a gentle slope. At the same time, the mounds of different scales are developed on the edge of the Gaoshi platform, and the height difference of the paleogeography is relatively large. Alternatively, the main area of the Moxi area is dominated by the relatively gently undulating platform surface, on which small-scaled residual mounds and depressions scatter. Finally, it can be seen from the overlay of the restoration of paleogeography and the distribution of fracture distribution that the distribution of the karst microgeography unit is obviously controlled by paleofaults.

The Jingbian gas field is located in the secondary paleogeographic unit--the karst slope area. The gas field microgeographic unit shows a unique paleokarst geography with coexistence of troughs and platforms. Therefore, the paleogeography unit is relatively simple, with only Level-III paleogeographic units such as platform mounds, slopes, and troughs.

It can be seen that the distribution of the karst paleogeography at the top of the Sinian system in the Anyue gas field is more complicated. First, the microgeography is various; second, the differentiation and characteristic difference of the microgeography in different blocks are also considerable; third, the distribution of microgeographic units is obviously affected by factors such as the paleofaults, lithology, and structural up-and-rise differences. Compared with the Sinian gas reservoir in the Anyue gas field, the karst paleogeographic units of the Upper Paleozoic gas reservoir in the Jingbian gas field are relatively simple in types, and the macroscopic distribution is only characterized by the relatively monolithic karst slope paleogeographic distribution featuring "high in west and low in east."

4.5. The Continuity and Connectivity of the Sinian Gas Reservoir in the Anyue Gas Field is Limited, Which are Different from the Relatively Stable Reservoir Continuity and Connectivity in the Jingbian Gas Field. Under the influence of differential tectonic movement and platform-type sedimentary model, the mound-beach sedimentary complex occurs in the Sinian gas reservoir of the Anyue gas field, which have laid a material foundation for the development of paleokarst reservoir rocks. Affected by the Tongwan movement, in the middle and late stages of the Dengying period, the southern China land mass generally rose, especially for a marginal area of the platform. The platform area was exposed on the surface, subjected to different degrees of denudation, and developed with fractured-vuggy high-quality reservoirs. In the meantime, the development degree and scale of high-quality reservoirs 
(fracture-cavity-type and pore-vug-type) are controlled by the mound-beach body, karst microgeographic unit, and karst structure, and the continuity and connectivity of effective reservoirs are limited (Figure 4).

For the Jingbian gas field, on the one hand, the overall sedimentary environment of the Ma-5 Member is characterized by evaporative tidal flat sedimentary facies, and the lithology in the vertical direction is seen with regular variation, while the lithology distribution in the lateral direction is stable, with good continuity and connectivity. On the other hand, in the weathering karst period, the overall Jingbian gas field was located in the karst slope, and the karst development degrees are relatively stable in the vertical and lateral directions. The boundary of the effective reservoir is controlled by troughs at different levels, and the trough of the drainage channel divides the gas reservoir into multiple relatively isolated blocks. Within each block, effective reservoir development is stable, with good continuity (Figure 5).

4.6. The Structural Edge Water is Developed in Local Areas of the Sinian Gas Reservoir in the Anyue Gas Field, Which is Different from the Extremely Complex Gas-Water Distribution in the Jingbian Gas Field. The gas-water distribution of the Sinian gas reservoir in the Anyue gas field is relatively simple, though the gas-water relationship in the platform margin of the Moxi block is more complicated. In the Moxi block, natural gas accumulates in the upper submember of Deng- 4 Member, and there is edge water in the north of the platform margin of the Moxi block. Well Moxi-022-x2 in the local low-lying area of the gas reservoir and the down-dip Well Moxi-102 encounter aquifers, yet with limited aquifer distribution, low water production, and low pressures of water bodies, which suggests the local occlusion of water (Figure 6). The gas-water distribution in Jingbian gas field is relatively complicated. Due to the nonuniform dissolution and structural reversal, the southwestern part of the Jingbian gas field presents an "L-shaped" waterbearing area. The distribution of formation water is scattered, and there is no clear gas-water interface, with no structural control, which represents the characteristics of the retention water between layers $[38,39]$ (Figure 7 ). It is found that the distribution of formation water is controlled by reservoir boundaries, troughs, and microstructures, and is mainly distributed at the reservoir pinch-out, the upward part of the trough, the low position of the structure, and the nose concave of the nose-like structure.

In summary, the Sinian gas reservoir in the Anyue gas field is an ancient weathering-crust carbonate rock gas reservoir controlled jointly by sedimentation+ karst, while the Jingbian Lower Paleozoic gas reservoir is a karst-controlled weathering-crust carbonate rock gas. The planar area of overlain favorable mound-beach bodies and microgeographic development unit of the Sinian gas reservoir in the Anyue gas field is a favorable reservoir development area, and from vertical perspectives, the favorable development formation series is the upper-middle part of the Deng-4 Member affected jointly by Tongwan-II and Tongwan-III episodes. Different types of reservoirs are developed, and the reservoir heterogeneity is strong. Due to the close proximity of the source rock in the Anyue-Deyang rift trough, the degree of natural gas charging is relatively high, and the bottom water occurs in some areas. The Sinian gas reservoir rocks are affected by multistage tectonic movements and deep hydrothermal fluids, resulting in the development of faults and microcracks at different levels together with strong reservoir heterogeneity. The overall reservoir is characterized by the development of storage space attributed to multiscaled pores, fractures, and caverns, and storage-flow bodies of different scales and types are stacked or isolated in three-dimensional space, with inactive formation water. Also, the gas well productivity varies significantly, and so does stable production capacity. The effective reservoir of the Lower Paleozoic gas reservoir in Jingbian is mainly developed on the karst slope in the favorable microgeographic unit. In the vertical direction, it is mainly developed in the thick layer consisting of 2 and 3 sublayers. The reservoir is seen with multiple gasbearing layers. The high production of wells is controlled by the effective reservoir thickness and the degree of microcrack development. The reservoir in the main area is better than that around the margin with low permeability. Due to the low degree of natural gas charging and structural reversal, edge water is developed in the western and southern parts. The characteristics of the gas reservoir indicate approximately a pore-dominated reservoir. Different types of microfractures are developed, and multiple layers contain gas. Different levels of troughs have separation effects on the integrity of the gas reservoir. The physical properties of the main area are superior to those of the marginal area, and some local areas are seen with active formation water. The production dynamics characteristics of each single well vary greatly.

\section{Comparative Analysis of Development Strategies and Technologies}

Both gas reservoirs are karst weathering-crust carbonate rock gas reservoirs. The similarities and differences of gas reservoir characteristics lead to the similarity and discrepancy in the development of the two gas reservoirs.

5.1. Both Reservoirs Need to Carry Out Selection of Gas Enrichment Areas, but Considerations are Different. The Sinian gas reservoir in the Anyue gas field and the Lower Paleozoic gas reservoir in the Jingbian gas field are both karst weathering-crus carbonate rock gas reservoirs. Due to impacts from reservoir development heterogeneity, both gas reservoirs require identification of gas enrichment areas during gas recovery. However, there are differences in considerations.

The Sinian gas reservoir in the Anyue gas field focuses on the study of sedimentology, microgeography, and fracture development characteristics in the gas enrichment area identification process. However, for the Lower Paleozoic gas reservoir in the Jingbian gas field, there are few studies on sedimentary characteristics involved in identifying gas accumulation areas, which instead emphasizes only on microgeography and fracture development characteristics (as shown in Figure 8). First, the development patterns of paleogeography for the two gas reservoirs decide screening of gas enrichment areas for hydrocarbon recovery, while the distribution characteristics of karst microgeography play a vital role in 


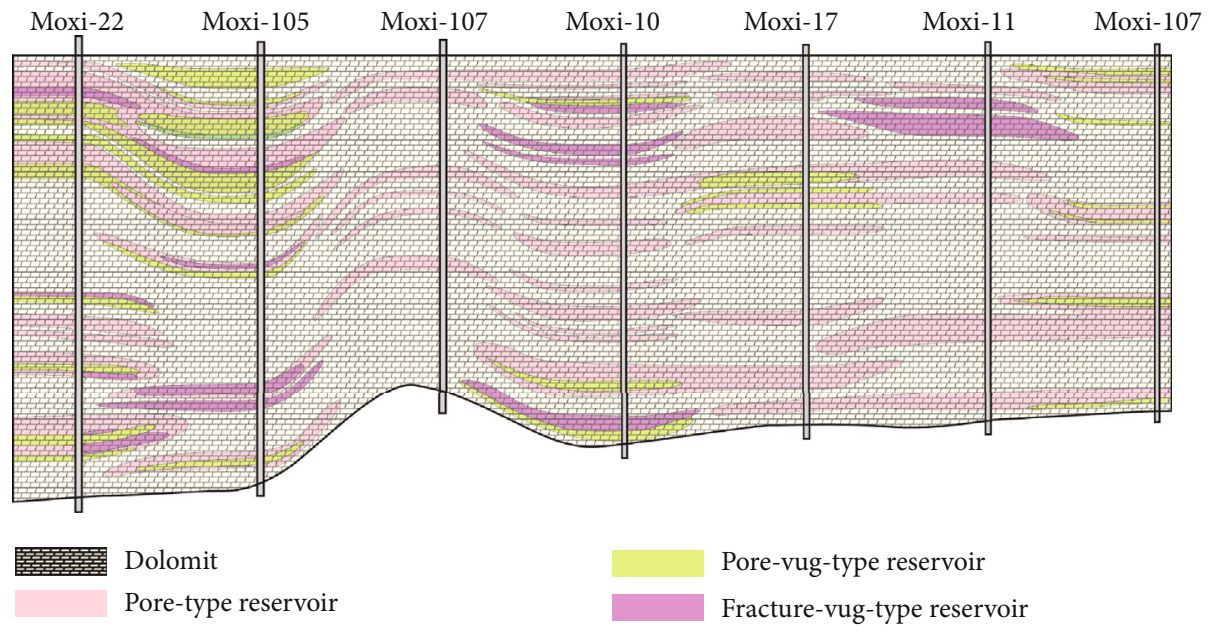

Figure 4: Cross-section of the Sinian gas reservoir in the Anyue gas field.

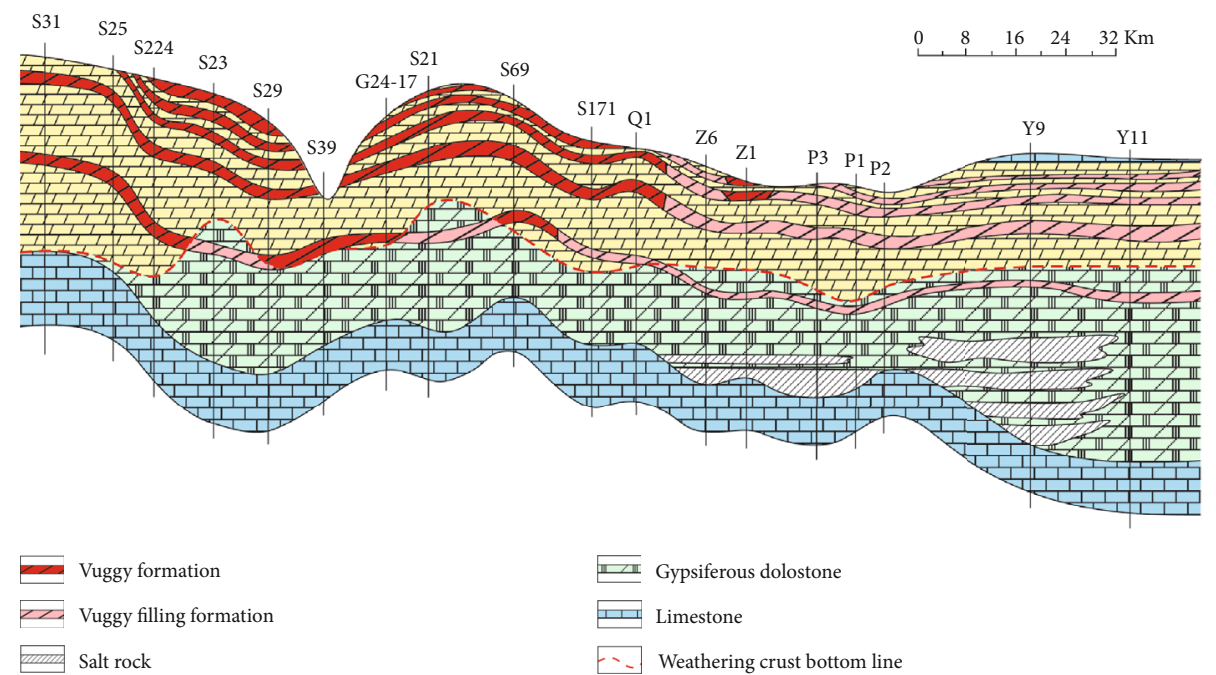

Figure 5: Cross-section of the Lower Paleozoic gas reservoir in the Jingbian gas field.

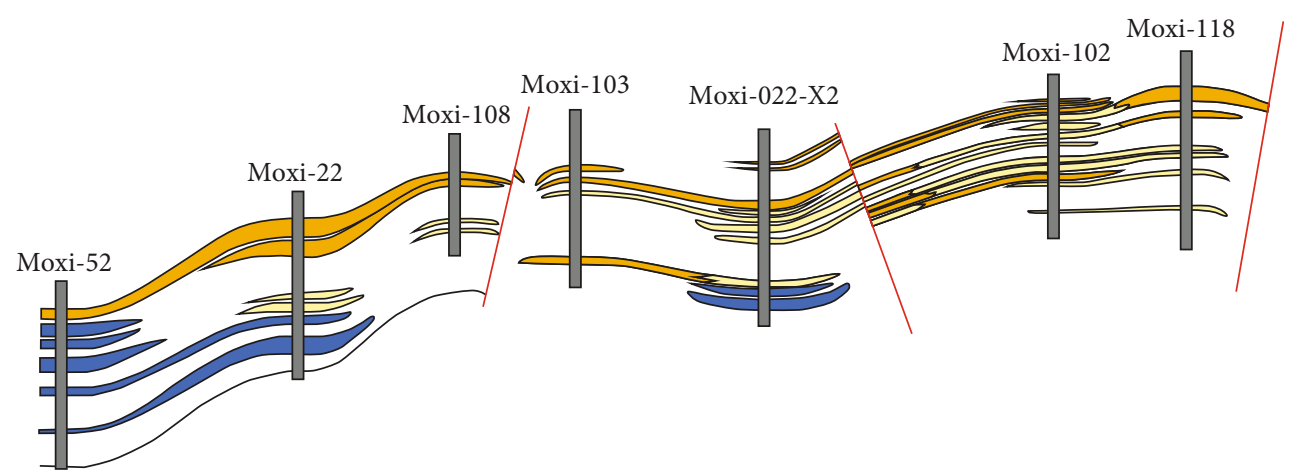
$\square$ Poor gas zone
$\square$ Gas zone
Aquifer

Figure 6: Cross-section of the Sinian gas reservoir of the Moxi block in the Anyue gas field. 


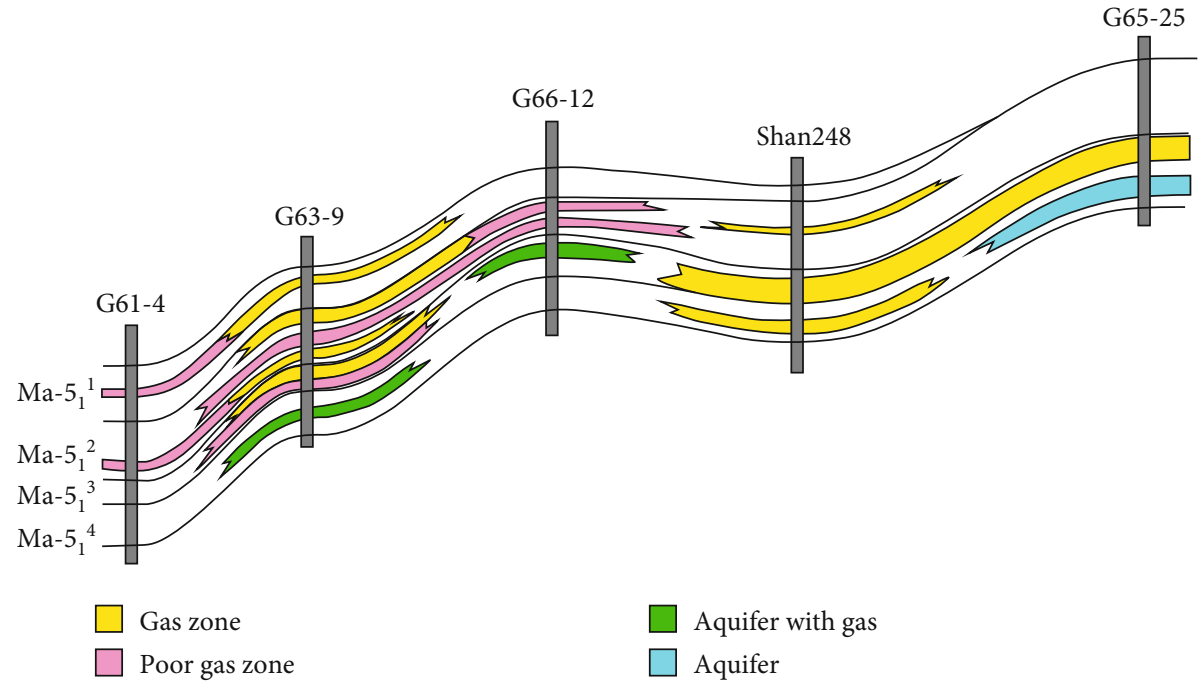

Figure 7: Cross-section of the Lower Paleozoic gas reservoir of the Jingbian southern gas field.

well placement. Taking the Jingbian Lower Paleozoic gas reservoir as an example, regardless of being a prospecting, evaluation, or development well, it is necessary to avoid troughs at different levels during the well location placement, and favorable residual mounds and slope positions are preferred. Furthermore, for carbonate rock gas reservoirs, the development degree and scale of microcracks are always the key to high gas production. Therefore, fracture description, classification evaluation, and studies of mineral filling characteristics, distribution characteristics are important for gas accumulation areas of both the two karst weathering-crust carbonate rock gas reservoirs. Finally, controlled by the sedimentary environment and facies, the Sinian gas reservoir is of the moundbeach sedimentation of the open platform, and the moundbeach bodies with different scales and shapes change regularly in three-dimensional space. Due to control of the moundbeach body scale, the effective reservoir presents itself as "lump-like" structures in a planar view, while being stacked vertically or laterally connected. The effective reservoir is quite isolated and has limited connectivity. The Lower Paleozoic gas reservoir in the Jingbian gas field is of the evaporative tidal flat deposition, and the effective reservoir is characterized by good planar stratification. It can be seen that the screening process of the Sinian gas reservoir enrichment area focuses on the description of the size, continuity, and connectivity of the mound-beach body. On contrary, the effective reservoir continuity of the Lower Paleozoic gas reservoir is good. The effective reservoir with thickness of $1-4 \mathrm{~m}$ is seen with largearea distribution mostly along the buried platform, while that with thickness greater than $4 \mathrm{~m}$ is distributed in the form of massive blocks. Limited effects of sedimentation are imposed upon development scales of effective reservoirs, and therefore the sedimentary factors are often not excluded in identifying gas enrichment areas.

5.2. Irregular Well Patterns are Used in Both the Two Gas Reservoirs, Yet with Varied Development Well Patterns. Influenced by sedimentation and diagenesis, the effective Sinian gas reservoir presents itself as "lumps" on the plane, and the effective reservoirs in the vertical direction from bottom to top evolve from being isolated to laterally connected and then to vertically stacked. The overall effective reservoir has a limited range of connected range over the plane. The Lower Paleozoic gas reservoir is endowed with good stratification and stable development. The development units relatively isolated by troughs present good internal effective reservoir continuity, still with internal variations of physical properties, thickness, and fracture development. The difference in geological characteristics determines that both the two gas reservoirs need to adopt irregular well patterns in the development process, and optimize the well pattern and well spacing to enhance the development revenue and ultimate recovery factor. In the process of well location placement, the Sinian gas reservoir implements screening of development well locations with respect to sedimentology, paleogeography, microcracks, etc. Moreover, through well type and trajectory optimization, the gas field mainly uses highly deviated wells (in some local high-quality reservoir areas, with horizontal wells), to connect more fracture-cavity systems, increase the contact area between the wellbore and the effective reservoir, promote the reservoir-encounter ratio and the proportions of Type-I + II wells, and ultimately stimulate the single-well production. As for developing the Lower Paleozoic gas reservoir, the early focus is set on the study of the controlling factors of high production of gas wells, and the reasonable well placement as an attempt to achieve sparse well placement and yet high gas production to improve the development efficiency of the gas reservoir. Due to the fact that multiple gas-bearing layers exist, vertical wells are often used for development. In the middle and late development stages, on the basis of the dynamic and static comprehensive description of the gas reservoir, the main area enhances the gas recovered degree with the help of infilling vertical wells, and the peripheral low-permeability area improves the producing degree of this area using horizontal wells. Finally the formation-pressure-charging recovery is implemented 


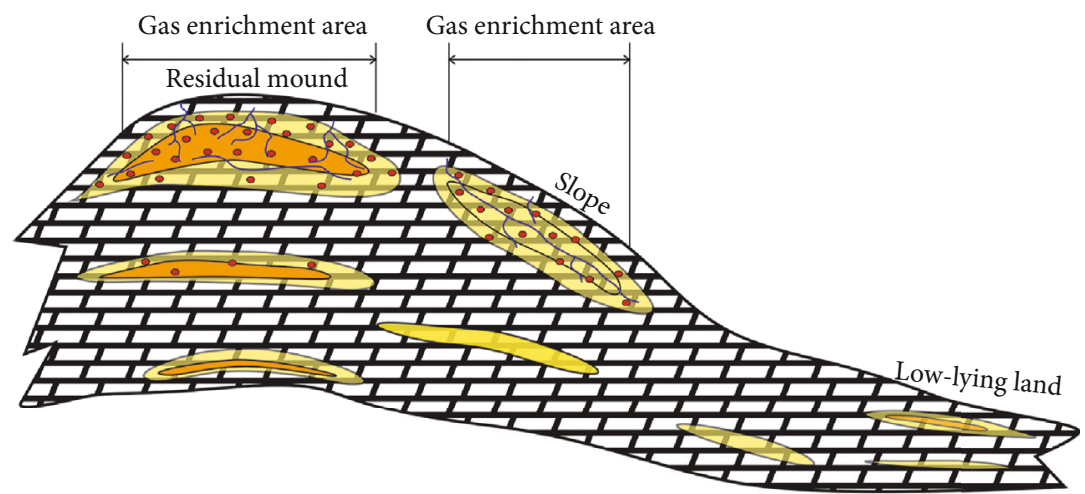

Schematic selection pattern of gas enrichment areas of the Anyue Sinian gas reservoir
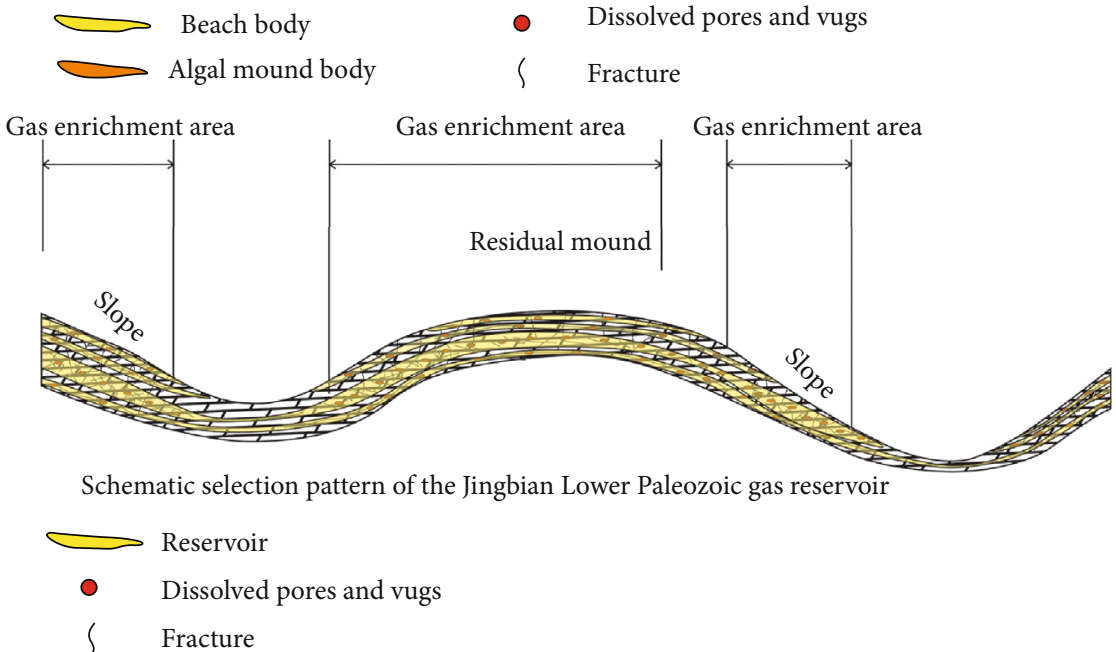

FIGURE 8: Selection patterns of gas enrichment areas in the types of gas fields.

whenever the timing comes, with appropriate pressure-charging methods, to tap the potential of gas reservoir development.

\subsection{Huge Differences are Seen in Gas Well Dynamic} Characteristics, While Different Production Stabilization Methods are Implemented. For the Sinian gas reservoirs, the effective reservoirs are mainly of fracture-cavity and porevug types, in which the storage space is mostly attributed to pores and fractures that serve as the main flow channels $[40,41]$. The good configuration of fractures and pores is the root cause for high production and stable production of gas wells. Controlled by the degree of fracture development and the development of the vuggy layer, gas well productivity, decline rate, single-well-controlled reserves and drainage area all present large differences. Taking Well Gaoshi-3 as an example, the production rate achieved during well testing amounted to $96 \times 10^{4} \mathrm{~m}^{3}$, with the open flow capacity of $158 \times 10^{4} \mathrm{~m}^{3}$. The well testing interpretation shows permeability of $0.58 \mathrm{mD}$ in areas far away from wells, and multiple fracture-cavity systems are connected. The dynamic reserve calculated in the evaluation exceeded $60 \times 10^{8} \mathrm{~m}^{3}$, with a drainage area of $6.0 \mathrm{~km}^{2}$. It was put into production in April 2014. The well maintains stable production at $30 \times 10^{4} \mathrm{~m}^{3} / \mathrm{d}$. At present, the cumulative gas production reaches $3.1 \times 10^{8}$ $\mathrm{m}^{3}$, and the production remains stable. Compared with Well
Gaoshi-3, the discovery well, Gaoshi-1 in the Sinian gas reservoir is seen with poor performance. The well has a testing production rate of $32 \times 10^{4} \mathrm{~m}^{3}$, with open flow capacity of 72 $\times 10^{4} \mathrm{~m}^{3}$. The well testing indicates obvious low-permeability characteristics, and the dynamic evaluation gives estimates of reservoirs of $3-6 \times 10^{8} \mathrm{~m}^{3}$, with a drainage area of $0.7 \mathrm{~km}^{2}$. The well was put into production in September 2012 and was intermittently producing at $5-8 \times 10^{4} \mathrm{~m}^{3} / \mathrm{d}$. The accumulated gas is $0.7 \times 10^{8} \mathrm{~m}^{3}$, and the current tubing pressure is only 12.4 MPa. The dynamic characteristics of the Lower Paleozoic gas reservoirs in the Jingbian gas field also show great differences. Taking well-controlled dynamic reserves as an example, the well-controlled dynamic reserves of the gas reservoir range from $0.8 \times 10^{4} \mathrm{~m}^{3}$ to $11.2 \times 10^{8} \mathrm{~m}^{3}$, with an average of $2.2 \times$ $10^{8} \mathrm{~m}^{3}$; the cumulative gas production is of $0-7.6 \times 10^{8} \mathrm{~m}^{3}$, with an average of $1.06 \times 10^{8} \mathrm{~m}^{3}$, which indicates large variations.

Nevertheless, there are differences in the two types of gas reservoirs with respect to production stabilization methods. The Lower Paleozoic gas reservoir in Jingbian is dominated by block replacement and assisted by interwell replacement, while the Sinian gas reservoir in the Anyue gas field primarily adopts well replacement for production stabilization, with supplementary block replacement (Figure 9). Since the Lower Paleozoic gas reservoir exhibits nearly laminated characteristics, the main 


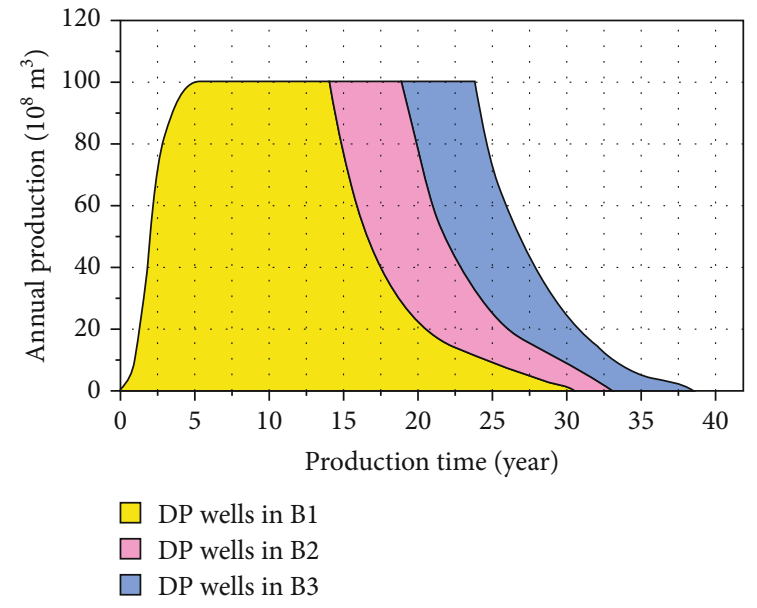

(a)

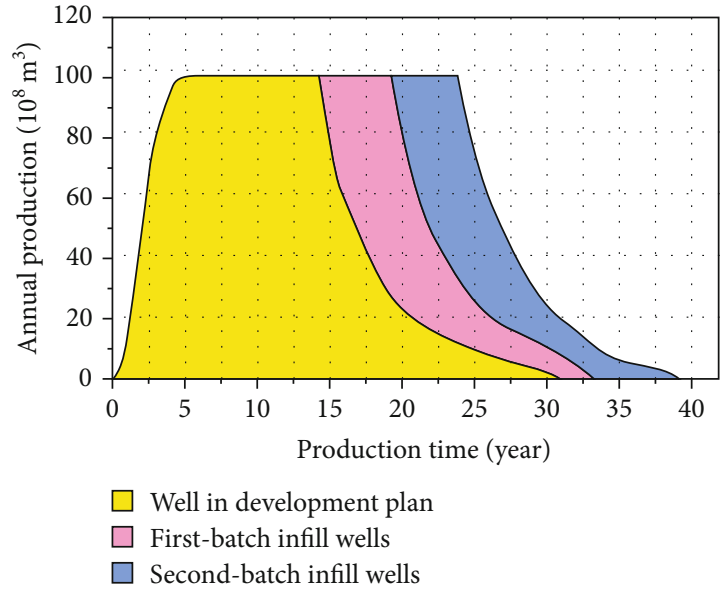

(b)

FIGURE 9: Block-replacement production stabilization pattern (a) and well-replacement production stabilization pattern (b).

area can be developed with one-time well placement and onetime well pattern construction. In the later stage, the gas reservoir stabilizes its long-term production mainly through boundary expansion. The production capacity building in the early stage was implemented in a block-wise manner, and from 1997 to 2000, it has achieved a production capacity of 3.2 billion cubic meters through production capacity establishment in six well blocks. From 2001 to 2003, the overproduction capacity of the gas reservoir reached 5.5 billion cubic meters, via the production capacity building in three well blocks. Then, from 2009 to 2013, through the old well pressurization, infill drilling in the main area, and the production capacity building of the eastern buried platform, the stable production of 5.5 billion cubic meters was maintained. From 2013 to 2017, the production block, Shan-251 block starts to build the production capacity, and the annual output of 5.5 billion cubic meters was again maintained. This gas reservoir can maintain its annual output of 5.5 billion cubic meters until 2022 through replacement of the Upper Paleozoic formation series and reservoir boundary expansion. As the effective reservoir Sinian gas reservoir, it is characterized by "lump-like" distribution. With identification of control factors of high production of wells and the realization of effective karst body characterization, the one-time well placement and one-time well pattern construction can also be achieved for development wells of the Deng-4 Member. Then, the long-term production is maintained primarily through tapping potential of the Deng-2 Member and corresponding development well placement, which enables replacement between wells. In the early development stage, after production capacity of the Gaoshiti and Moxi areas are established, the Sinian gas wells can maintain stable production for 5-8 years, in the case of scientific evaluation of the gas well production capacity, the Sinian gas well can maintain a stable production period of 5 to 8 years, and thus the gas reservoir production can be stabilized at a reasonable development scale. In the later stage, through the multilayer three-dimensional development and the remaining reserve tapping (on the one hand, through the development appraisal and nonuniform well placement in the
Deng-2 Member; on the other hand, via the supplementary development wells and improved well pattern of the Deng-4 Member), the long-term stable production of the gas reservoir can be maintained by the replacement of wells. Meanwhile, each block inside the platform of the Sinian gas reservoir possesses certain development potential, which is to some extent able to provide production capacity supplement to the Sinian gas reservoir and reduce the production capacity building risk.

5.4. Reconstruction of the Gas Reservoir is of Necessity for Economically Effective Development in Both Gas Reservoirs, but the Technologies for Reservoir Stimulation are Different. Due to the special lithology, physical properties, storage space, and fluid properties of carbonate rock reservoirs, most of development of carbonate rock gas reservoirs requires reservoir stimulation to achieve economic benefits. This is the case in both the Jingbian Lower Paleozoic and Gaomo Sinian gas reservoirs. The Lower Paleozoic Ordovician Majiagou Formation dolomite reservoir in the Jingbian gas field represents a low-pressure and low-permeability gas reservoir. At the beginning of the Jingbian gas field development, for the purpose of removing near-wellbore pollution and increasing the length of the acid-etched fracture, a variety of technologies such as normal-acid acid fracturing and gelled-acid acid fracturing and acid fracturing involving multistaged injection were developed. With the infill drilling and boundary expansion in production capacity establishment, the encountered reservoir is becoming increasingly tight and the mineral composition has changed. For the purpose of deep reservoir reconstruction, propped fracturing and cross-linking acid propped fracturing are carried out in carbonate reservoirs, which are seen with relatively good results. In the meantime, the horizontal well reservoir stimulation technology has also achieved preliminary results. With the progress of the gas reservoir development, reservoir stimulation faces some new problems: (1) The physical properties of the surrounding area of the gas field for production capacity supplement deteriorate, and the output per well is 
low. The surrounding production capacity replacement area is mainly seen with Type-II + III wells, while the reservoir is thinner and tighter and the filling mineral composition has changed. The single-well production after stimulation is low. (2) The horizontal well extends to the periphery of the gas field and the boundary tight reservoir, which makes it difficult to increase the production per well. With the placement of horizontal wells in the periphery and tight reservoirs of the gas field, the horizontal well acidizing technology has failed to meet the requirements for improving the development efficiency of horizontal wells. First, this is due to the deteriorated physical properties of the reservoir, which lead to the failure of acidizing to achieve deep-area reconstruction. Second, owing to the reservoir heterogeneity, the nonselective acidizing across the whole wellbore ends with excessive acidizing or insufficient acidizing intensity. Third, given low formation pressures, large-scale acid injection, and massive volume of the wellbore, the flow back period is prolonged. (3) The proportion of low-yield and low-efficiency wells in the main area of the gas field is high, and restimulation is urgently needed. In response to these problems, for the infilldrilling area and the surrounding replacement area, the stimulation for Type-I reservoirs mainly adopts the deeppenetration acid fracturing, while that for Type-II and III reservoirs is primarily implemented using propped fracturing and cross-linking acid propped fracturing for carbonate rock reservoirs. For the horizontal well reservoir reconstruction, the coiled tubing-based uniform acid placement + acidizing technology is adopted to realize the whole-wellbore-section stimulation, and the horizontal well multistage acid fracturing technology is developed. For the restimulation of old wells, the low-production wells are selected to carry out low-damage well killing using lost-circulation-proof killing fluids and snubbing operation equipment for low-pressure gas payzones, and the propped fracturing technology is used to achieve deep reconstruction.

The Sinian reservoir is characterized by deep depth, high temperature, presence of sulfur, low porosity, low permeability, strong heterogeneity, and various reservoir types. The following reservoir stimulation difficulties are encountered in the practice of reservoir reconstruction: (1) The reservoir type and the fracture-cavity relationship are complex. The Sinian Deng- 4 gas reservoir can be mainly divided into the fracturecavity type, pore-vug type, and pore-dominated type. The reservoir types are diverse, and the pores, vugs, and fractures are scattered, which results in a complicated configuration. A single stimulation technology process makes it difficult to achieve effective reconstruction over different reservoir types, and it is necessary to adopt a stimulation technology specific to the characteristics of different reservoir types. (2) The characteristics of low porosity and low permeability of the reservoir are obvious. The porosity for cylinder core samples of the reservoir averages $3.87 \%$, the average permeability is $0.51 \mathrm{mD}$, the full-diameter core sample porosity averages $3.97 \%$, and the horizontal permeability averages $2.89 \mathrm{mD}$. The fracture-cavity and pore-vug reservoirs are highly developed, with porosity surpassing $3 \%$ and permeability over 0.1 $\mathrm{mD}$, which are high quality. The porosity of the poredominated reservoir is between $2 \%$ and $3 \%$, and the dissolved vug is underdeveloped. Moreover, the connectivity between vugs is inferior, and the permeability is mostly less than 0.01 $\mathrm{mD}$, which is much smaller than that of the pore-vug and fracture-cavity reservoirs. In terms of simulation of the lowpermeability reservoir, coming-into-being of long effective fractures is desirable, and the deep acid fracturing or deeppenetration acidizing technologies are required to restore or increase the gas well production. (3) The reservoir is highly heterogeneous. The Sinian Dengying Formation has a large reservoir thickness together with a large number of vertical layers, and is difficult to recover effectively. The lateral uniform acid placement is challenged, and whether the acid system and the acidizing technology can achieve uniform placement of acid across multiple layers is a main factor that directly affects the postacidizing well performance. (4) There is no obvious interlayer between the upper and lower Deng- 4 submembers. It is difficult to achieve zonal acidizing by mechanical zonal isolation tools for acidizing. (5) The reservoir temperature is high, which results in rapid the acid-rock reaction, short effective distance of acids, and limited length of the acid etching fracture. Meanwhile, technical breakthrough regarding temperature limitation should be made in both the injection process and the acid system, to as much as possible expand the swept volume of the acid. (6) The reservoir has high Young's modulus and large closure stress (the closure pressure is about $110 \mathrm{MPa}$ ). It is difficult to open the bottom-hole fracture and also maintain a high-conductivity flow channel after the fracture is formed. The acid fracturing technology is supposed to be able to effectively open the fracture and intensify uneven etching of the fracture surface. Three sets of main stimulation technologies are developed in the early development stage, given the reservoir characteristics, namely, retarded-acid fracturing, deep acid fracturing, and complex-fracture-network acid fracturing. In the later stage, given the complex lithology and storage space of the Dengying Formation reservoir (coexistence of multiple types of storage space), and strong heterogeneity both on a single-well and regional basis, promising and nonpromising wellbore sections are separated for reservoir stimulation in accordance with the segmentation principle based on reservoir properties, in order to improve the applicability and effectiveness of reservoir reconstruction. Accordingly, the layerspecific stage-specific reconstruction practice for the main body of the gas reservoir has been developed, in which practices and fluid and operation parameters specific to the task target are adopted. As the gas reservoir development gradually migrates toward the inside of the platform, technical breakthroughs on stimulation practices for reservoirs with low permeability, multiple layers, low thickness, and high siliceous contents are of extreme urgency.

\section{Inspirations for the Development of Sinian Gas Reservoir in Anyue Gas Field}

The Jingbian Lower Paleozoic gas reservoir is the first largescale carbonate rock gas reservoir that is discovered and put into successful development in China. Its development history and development experience have great guiding significance for the development evaluation, large-scale production building, and determination of development countermeasures as 
well as improving the efficiency of gas reservoir development and improve the gas reservoir management level.

\subsection{Laying Solid Foundation for Efficient Sinian Gas} Reservoir Development by Refining Research on Sedimentary Characteristics. Although the Jingbian Lower Paleozoic gas reservoir and the Gaomo Sinian gas reservoir are both karst weathering-crust carbonate rock gas reservoirs, and the control factors of effective reservoirs are not the same. In terms of the Jingbian Lower Paleozoic gas reservoir, effective reservoirs are mainly controlled by karst paleogeography, while the effective Sinian gas reservoirs are not only controlled by karst paleogeography, but also subjected to major influences of sedimentary facies on the effective reservoir development dimension, scale, and physical properties. The study of the sedimentary facies of the Sinian gas reservoir in the Anyue gas field should focus on the following three aspects: (1) First, fine description of the distribution and characteristics of the margins of the platform. Because the sedimentary environment of the Dengying Formation in the Gaomo area is of a local platform facies, the characteristics of the platform edge and distribution range play important roles in the development of the mound-beach facies. (2) Second, one must understand the distribution characteristics and distribution patterns of the mound-beach body. Under the control of microbial development, the development characteristics of the mound-beach bodies are different from those of the reef-beach bodies. The main controlling factors of development, the scale and morphology, vertical evolution, planar distribution characteristics, and distribution patterns of the mound-beach bodies are the basis for the study of the development characteristics of karst reservoirs, which to some extent decide the dimension and scale of the karst body. (3) Third, the fine characterization of the interior of the mound-beach body is conducive to the study on control factors of high production of wells. Whether the internal structure of the microbial mound is similar to that of reefs and the relationship between favorable facies types and microfacies in the mound-beach body, these problems have always been fundamental problems that restrict the study of ancient carbonate rock sedimentary facies.

6.2. Studies on the Distribution Pattern and Characteristics of Paleogeography is the Key to the Rapid Establishment of the Sinian Gas Reservoir. Paleogeography is undoubtedly the controlling factor for the development of effective reservoirs in karst weathering-crust carbonate rocks, and still there are differences in reference to dominance and degrees of effects. For karst weathering-crust carbonate rock gas reservoirs, the restoration and fine characterization of karst paleogeography can accelerate gas exploration and production progresses. Taking the Jingbian gas field as an example, the gas field has experienced four large-scale industrial mappings to improve the understanding of karst paleogeography: (1) On the basis of analyses of sedimentary backgrounds and paleostructural features, the concept of "paleoburied platform" was proposed, and the developed karst paleogeography map did not only open the width of thinking of gas exploration in the stable platform area, but also resulted in successful discoveries of industrial streams from the first placed three exploratory wells penetrating into the weathering-crust dissolution caverns. (2) In accordance with the understanding of "beaches inside the platform and troughs outside the platform," the major NStrending trough has been identified in the front of the Jingbian karst terrane, which plays an active role in the exploration of natural gas in the $260 \mathrm{~km}$ long (north-south) and $40 \mathrm{~km}$ wide (west-east) range and the rapid confirmation of the large-scale gas field. (3) As the exploration continues, with supplement of drilling data and improvement of the seismic prediction data, the NS-spreading of the major trough has been changed and the overall trend from west to east has been predicted, which thus provides a geological basis for the continuous eastward expansion of the gas-bearing layer. (4) The morphology of karst paleogeography and the development characteristics of the paleotrough network are further refined to provide a basis for broadening the prediction for new targets in the exploration field, and also guidance for production stabilization based on infilling wells. It can be seen that the study of the distribution characteristics and patterns of karst paleogeography is vital for the exploration breakthrough, exploration, expansion, rapid production capacity building, and long-term stable production of the Jingbian karst weathering-crust carbonate rock gas reservoirs. Therefore, for the Gaomo Sinian karst weathering-crust carbonate rock gas reservoir, the paleogeographic distribution model should be used to identify the favorable area for development, while the paleogeographic distribution characteristics and the microgeography are finely depicted for well location placement. The current research shows that the paleogeographic distribution characteristics of the Gaomo Sinian gas reservoir is highly complicated, and the differences of the Gaoshiti and Moxi paleogeography distribution are clear. Meanwhile, the microgeography inside the different blocks, especially the Moxi block, is highly varied. Therefore, in a subsequent study, one should continuously refine the understanding of the distribution features of microgeography, and compare and analyze the differences of microgeography distribution characteristics in different lithologies, different blocks (Gaoshiti and Moxi), and sedimentary environments (platform margin and platform interior), to demonstrate the role of faults in controlling the distribution characteristics of paleogeography, and to analyze the correlation between fracture development and microgeography units, ultimately so as to guide the development well location placement.

\subsection{Finely Characterizing the Distribution Characteristics of} Fault Systems is the Core of Efficient Development of the Sinian Gas Reservoir. Fault systems, especially fractures, are of great significance for efficient development of oil and gas reservoirs. For carbonate rock gas reservoirs, the development scale and degree are undoubtedly two important factors for high gas production. Taking the Jingbian Lower Paleozoic gas reservoir as an example, the $\mathrm{Ma}-5_{1+2}$ reservoir is developed with structural and weathering ruptures. In the high-quality reservoir, the dissolved pores with stratified distribution often serve as the main storage space, and the network fractures are seepage channels, which greatly improve the reservoir conductivity (as shown in Table 2) and help improve gas well productivity. Because of the strong correlation between development 
TABLE 2: Porosity and permeability of fractures and pores in the Ma- $51+2$ reservoir.

\begin{tabular}{|c|c|c|c|c|}
\hline Item & Wireline logging & Core sample fracture & Well testing interpretation & Comprehensive evaluation \\
\hline$\Phi_{f}(\%)$ & $\begin{array}{c}0.002-0.048 \\
\text { Average: } 0.0132\end{array}$ & $\begin{array}{c}0.0124-0.387 \\
\text { Average: } 0.1631\end{array}$ & $\begin{array}{c}0.0008 \sim 0.1078 \\
\text { Average: } 0.0411\end{array}$ & 0.034 \\
\hline$k_{f}\left(10^{-3} \mu \mathrm{m}^{2}\right)$ & $\begin{array}{l}0.0062-2997.0 \\
\text { Average: } 4.815\end{array}$ & $\begin{array}{c}\text { 9.01-11797.37 } \\
\text { Average: } 2816.44\end{array}$ & $\begin{array}{l}0.0363 \sim 29.953 \\
\text { Average: } 4.074\end{array}$ & $1 \sim 30$ \\
\hline
\end{tabular}

of faults and fractures, it is of important guidance to study the distribution characteristics of faults and evaluate their stages and levels. Since the Sinian system is an ancient carbonate rock reservoir, and the Sichuan Basin has experienced multicycle and multistage tectonic movements, leading to a multistage fault system in the Sinian Dengying Formation, how to identify and characterize fault systems of different stages and periods is critical to the division of the Gaomo area, zone-specific evaluation, validation of correlation of fracture development and faults of different stages and periods on the basis of lithologic and imaging logging data, analyses on the favorable microcrack development zone, and placement of high-production wells in the marginal area, and scaled-up recovery of reserves stored in the low-permeability area inside the platform.

6.4. Enhancing Dynamic Surveillance and Improving the Level of Refined Management Ensure the Stable and Efficient Development of the Sinian Gas Reservoir. The development dynamics surveillance and analysis of gas reservoirs is the core of gas field development management, and should be implemented from the start to the end of the gas field development. Through the implementation of a series of the dynamics surveillance technologies, a large amount of detailed data can be obtained, in terms of flow pressures, static pressures, gas quality, and water quality. The dynamic reservoir can be confirmed by gas reservoir pressure regime division based on the fluid distribution regularity, reservoir evaluation, and pressure field analysis. Using verification of dynamic reserves combined with the gas field production dynamics, well testing software and numerical simulation methods can be adopted to analyze the stable production capacity of gas fields. By scaling up the analysis from the stable production capacity of a single well to that of a block, the development indicators of each stage of the gas field are predicted, which provides a basis for the development of gas field production stabilization strategies. From the development history of the Jingbian gas field, it can be seen that the dynamics surveillance technology runs through the lifecycle of the gas field development, and four major technical series, namely, the pressure monitoring, gas well testing, fluid monitoring, and production monitoring, have been formed: (1) Pressure monitoring: a large number of high-frequency, full-coverage pressure monitoring data provide an important basis for determination of gas reservoir formation pressure distribution and variation, understanding gas well production drawdown pressure, verifying dynamic geological reserves on a single-well or block basis, and identifying wellbore fluid building-up. (2) Interference well testing: in 1993 and 1996, in order to understand the connectivity of the reservoir from a dynamic perspective, the interwell interference testing was carried out in the Lin-5 well group and the Shan-17 well group. The interference well testing was successful, and the results showed that the reservoirs in the area were interconnected laterally. (3) Fluid monitoring. (4) Zonal production monitoring: the statistical results of the gas production historic data over the years indicate that the main payzone of the Jingbian gas field is the Ma $-5_{1}{ }^{3}$ layer. Based on the dynamic monitoring, the development unit classification system standard was established, 36 development units of three categories were divided, and the technical countermeasures for stable production and potential tapping of different development units were proposed. The large-scale dynamic monitoring of the Jingbian gas field has improved the level of refined gas reservoir management and improved the efficiency of gas reservoir development. For the more complex Gaomo Sinian Dengying Formation gas reservoir, with respect to the gas reservoir characteristics, key development challenges, development stage, and dynamics surveillance technologies should be implemented selectively in a timely fashion so as to understand specific core issues during gas reservoir development, and seize each opportunity to execute corresponding measures, which is able to improve the fine management level of the Sinian gas reservoir in the Anyue gas field, and achieve smooth, stable, and efficient development of gas reservoirs.

However, it should be noted that although this work has conducted comprehensive analysis on gas reservoir characteristics and development strategies and technologies for carbonate gas reservoirs, the relevant results and recognitions are only applicable for Karst weathering-crust carbonate gas reservoirs. If the reservoir type is different from the mentioned reservoir, the development strategies and technologies that should be taken may be also varied. In addition, limited by the length of article, the prominent reservoir characteristics are compared and studied, but there are lots of formation features that should be analyzed indeed. Nevertheless, in general, when the reservoir type is similar to the reservoir type in this paper, then the studies for reservoir characteristics and development technologies can provide some guidance for operators to some extent.

\section{Summary and Conclusions}

The Sinian gas reservoir in the Anyue gas field and the Lower Paleozoic gas reservoir in the Jingbian gas field are both karst weathering-crust carbonate rock gas reservoirs. Through comparative analysis, the following conclusions and understandings are obtained: 
(1) Significant differences exist in gas reservoir characteristics between the Sinian gas reservoir in the Anyue gas field and the Lower Paleozoic gas reservoirs in the Jingbian gas field. (1) Gas reservoir types: the Sinian gas reservoir in the Anyue gas field represents a lithologic-structural trap with multiple structural high points and multiple fracture systems, which is different from the lithologic-stratigraphic trap associated with the Jingbian Lower Paleozoic gas reservoir featuring a west-trending monocline and multirowed nose-fold structures. (2) Sedimentary environment: the Sinian gas reservoir in the Anyue gas field is of a platform sedimentary facies under the tensile setting, while the Jingbian gas field is derived from the tidal flat facies in a stable craton. (3) Karst paleogeography: generally speaking, the top paleokarst of the Sichuan Basin is characterized by "three upheavals and two sags," and yet the Ordos Basin is seen with a relatively simple paleokarst environment displaying "high in central while low in west and east, and steep in west and placid in east." For the Gaomo area, the paleogeographic features of the Gaoshiti and Moxi blocks are considerably varied, which is distinct from the relatively simple distribution characteristics of the paleogeography in the main area of Jingbian. (4) Reservoir development characteristics: it was found that the Sinian gas reservoir in the Anyue gas field has limited connectivity and continuity. On the contrary, the Jingbian gas field presents relatively stable continuity and connectivity. (5) Fluid distribution characteristics: the structural edge water is developed in some local areas of the Sinian gas reservoir in the Anyue gas field, which is different from the highly complex gas-water distribution in the Jingbian gas field

(2) Differences in gas reservoir characteristics result in similarities and differences in development strategies and technologies. (1) Both gas reservoirs need to identify the gas enrichment area, yet with varied considerations. (2) Irregular well patterns are used in both cases, still with different development well patterns. (3) The gas-well-controlled reserves and production capacity present large differences between two reservoirs, and the gas reservoir production stabilization methods are also different. (4) Both the two reservoirs need to be reconstructed in order to achieve economic benefits, but the technical means of reservoir reconstruction varies

(3) The successful development of the Lower Paleozoic gas reservoir in Jingbian gas field provides good reference for production capacity building, long-term stable production, and scientific management of the Sinian gas reservoir in the Anyue gas field. For the Sinian gas reservoir, (1) the study of the fine sedimentary characteristics is the basis for the effective development of the gas reservoir; (2) the study of the distribution patterns and characteristics of the paleo- geography is the key to the rapid production building of the Sinian gas reservoir; (3) elaborate depiction of the fault system and the fracture distribution is the core of the efficient development of the Sinian gas reservoir; and (4) dynamics surveillance should be enhanced and the level of refined management should be improved so as to ensure the stable and efficient development of the Sinian gas reservoir

\section{Data Availability}

The data used to support the findings of this study are available from the first author upon request.

\section{Conflicts of Interest}

The authors declare no competing interests.

\section{Acknowledgments}

This work is supported by the National Science and Technology Major Project (2016ZX05015-003) and the CNPC Science and Technology Major Project (2016E-06). The authors are grateful for the help of Dongbo He, Yunsheng Wei, Lianjin Zhang, and Guoqiang Zheng during the revision of paper.

\section{References}

[1] W. Z. Zhao, A. J. Shen, W. Q. Pan, B. Zhang, Z. F. Qiao, and J. F. Zheng, "A research on carbonate karst reservoirs classification and its implication on hydrocarbon exploration: cases studies from Tarim Basin," Acta Petrologica Sinica, vol. 29, no. 9, pp. 3213-3222, 2013.

[2] W. Z. Zhao, G. Q. Wei, W. Yang et al., "Discovery of Wanyuan-Dazhou Intracratonic Rift and its exploration significance in the Sichuan Basin, SW China," Petroleum Exploration and Development, vol. 44, no. 5, pp. 659-669, 2017.

[3] A. L. Jia, H. J. Yan, J. L. Guo, D. B. He, L. H. Cheng, and C. Y. Jia, "Development characteristics for different types of carbonate gas reservoir," Acta Petrolei Sinica, vol. 34, no. 5, pp. 914923, 2013

[4] A. L. Jia and H. J. Yan, "Problems and countermeasures for various types of typical carbonate gas reservoirs development," Acta Petrolei Sinica, vol. 35, no. 3, pp. 519-527, 2014.

[5] J. Ailin, Y. Haijun, G. Jianlin, H. Dongbo, and W. Tiejun, "Characteristics and experiences of the development of various giant gas fields all over the world," Natrual Gas Industry, vol. 34, no. 10, pp. 33-46, 2014.

[6] X. Z. Li, Z. H. Guo, Y. J. Wan et al., "Geological characteristics and development strategies for Cambrian Longwangmiao Formation gas reservoir in Anyue gas field, Sichuan Basin, SW China," Petroleum Exploration and Development, vol. 44, no. 3, pp. 398-406, 2017.

[7] X. Wu, C. Ni, Q. Liu, G. Liu, J. Zhu, and Y. Chen, "Genetic types and source of the upper paleozoic tight gas in the Hangjinqi area, northern Ordos Basin, China," Geofluids, vol. 2017, Article ID 4596273, 14 pages, 2017.

[8] D. Liu, "Carbon and hydrogen isotopic reversals in highly mature coal-derived gases: a case study of paleozoic gases in the southern Ordos Basin, China," Geofluids, vol. 2019, 23 pages, 2019. 
[9] Z. He, Q. Ding, Y. Wo, J. Zhang, M. Fan, and X. Yue, "Experiment of carbonate dissolution: implication for high quality carbonate reservoir formation in deep and ultradeep basins," Geofluids, vol. 2017, 8 pages, 2017.

[10] D. Zhu, Q. Liu, J. Zhang, Q. Ding, Z. He, and X. Zhang, “Types of fluid alteration and developing mechanism of deep marine carbonate reservoirs," Geofluids, vol. 2019, 18 pages, 2019.

[11] R. Shekhar, E. Ewart, and C. Obeta, "Review of identification, characterization and modeling of different types of fault \& fracture systems in a giant offshore carbonate reservoir, UAE," in Abu Dhabi International Petroleum Exhibition \& Conference, Abu Dhabi, UAE, 2019.

[12] S. S. Shaima, A. M. Amr, H. B. Husain, and D. B. Djilali, "Review of the Lower Khuff reservoir petrophysical classification, offshore Abu Dhabi," in The Abu Dhabi International Petroleum Exhibition \& Conference, Abu Dhabi, UAE, 2019.

[13] L. Figuera, A.-H. Khaled, B.-A. Khaled, and F. Al-Aryani, "Performance review and field measurements of an EOR-WAG project in tight oil carbonate reservoir-Abu Dhabi onshore field experience," in Abu Dhabi International Petroleum Exhibition and Conference, Abu Dhabi, UAE, 2014.

[14] W. N. Diab and E. W. Al-Shalabi, "Recent developments in polymer flooding for carbonate reservoirs under harsh conditions," in Offshore Technology Conference, Brasil, Rio de Janeiro, Brazil, 2019.

[15] J. Hao, S. Mohammadkhani, H. Shahverdi, M. N. Esfahany, and A. Shapiro, "Mechanisms of smart waterflooding in carbonate oil reservoirs-a review," Journal of Petroleum Science and Engineering, vol. 179, pp. 276-291, 2019.

[16] K. Mogensen and S. Masalmeh, "A review of EOR techniques for carbonate reservoirs in challenging geological settings," Journal of Petroleum Science and Engineering, vol. 195, article 107889, 2020.

[17] X. Shengli, L. Zhenhong, W. Xin, and Z. Congbin, "Distribution and exploration potential of Ordovician reservoir in Ordos basin," Oil \& Gas Geology, vol. 27, no. 3, pp. 405-412, 2006.

[18] Y. U. Haifeng, L. I. Yong, X. U. Fanghao, W. Guo Zhi, and $\mathrm{X}$. Guo Sheng, "The fluid charge and hydrocarbon accumulation, Sinian reservoir, Anpingdian-Gaoshiti structure, Central Sichuan Basin," Acta Petrologica Sinica, vol. 30, no. 3, pp. 727736, 2013.

[19] D. U. Jinhu, Z. O. Caineng, X. U. Chunchun et al., "Theoretical and technical innovations in strategic discovery of a giant gas field in Cambrian Longwangmiao formation of Central Sichuan paleo-uplift, Sichuan Basin," Petroleum Exploration and Development, vol. 41, no. 3, pp. 267-277, 2014.

[20] K. Wang, X. Pang, Z. Zhao et al., "Geochemical characteristics and origin of natural gas in southern Jingbian gas field, Ordos Basin, China," Journal of Natural Gas Science and Engineering, vol. 46, pp. 515-525, 2017.

[21] Q. G. Li, K. S. Li, and H. Y. Tang, "Unconformity characteristics of Sichuan Basin and its geological implication," Natural Gas Technology, vol. 4, no. 6, pp. 21-26, 2010.

[22] W. E. Guoqi, Y. A. Wei, D. U. Jinhu et al., "Tectonic features of Gaoshiti-Moxi paleo-uplift and its controls on the formation of a giant gas field, Sichuan Basin, SW China," Petroleum Exploration and Development, vol. 42, no. 3, pp. 257-265, 2015.

[23] W. E. Guoqi, Y. A. Wei, J. Zhang et al., "The pre-Sinian rift in central Sichuan Basin and its control on hydrocarbon accumu- lation in the overlying strata," Petroleum Exploration and Development, vol. 45, no. 2, pp. 179-189, 2018.

[24] L. Bing, Z. Gang, L. Wenjun, and X. Maolong, "Discovery from exploration of lower Paleozoic-Sinian system in central Sichuan Palaeo-uplift and its natural gas abundance law," China Petroleum Exploration, vol. 20, no. 2, pp. 18-29, 2015.

[25] J. Zhou, J. Zhang, H. Deng et al., "Lithofacies paleogeography and sedimentary model of Sinian Dengying Fm in the Sichuan Basin,” Natural Gas Industry, vol. 37, no. 1, pp. 24-31, 2017.

[26] S. Qin, F. Li, Z. Zhou, and G. Zhou, "Geochemical characteristics of water-dissolved gases and implications on gas origin of Sinian to Cambrian reservoirs of Anyue gas field in Sichuan Basin, China," Marine and Petroleum Geology, vol. 89, pp. 83-90, 2018.

[27] W. Wang, X. Pang, Z. Chen et al., "Statistical evaluation and calibration of model predictions of the oil and gas field distributions in superimposed basins: a case study of the Cambrian Longwangmiao Formation in the Sichuan Basin, China," Marine and Petroleum Geology, vol. 106, pp. 42-61, 2019.

[28] M. D. Jin, Karst Reservoir of the Fourth Member of Dengying Formation in Moxi-Gaoshiti Area: Development Regularity and Forecasting, Ph. D. thesis. Southwest Petroleum University, 2014.

[29] J. Fu, X. Wu, L. Sun, Z. Yu, Z. Huang, and Z. Ding, "New understandings of the lithofacies paleogeography of the middle assemblage of Majiagou Fm in the Ordos Basin and its exploration significance," Natural Gas Industry, vol. 37, no. 3, pp. 916, 2017.

[30] W. Han, W. Ma, S. Tao, S. Huang, L. Hou, and J. Yao, “Carbon isotope reversal and its relationship with natural gas origins in the Jingbian gas field, Ordos Basin, China," International Journal of Coal Geology, vol. 196, pp. 260-273, 2018.

[31] D. Gong, J. Li, I. Ablimit et al., "Geochemical characteristics of natural gases related to Late Paleozoic coal measures in China," Marine and Petroleum Geology, vol. 96, pp. 474-500, 2018.

[32] Z. Wang, W. Zhao, S. Hu et al., "Control of tectonic differentiation on the formation of large oil and gas fields in cra-ton basins: a case study of Sinian-Triassic of the Sichuan Basin," Natural Gas Industry, vol. 37, no. 3, pp. 9-23, 2017.

[33] L. I. Hong, L. U. Sicong, T. A. Xiucheng et al., "Restoration of paleokarst geomorphology of SInian Dengying Formation in Sichuan Basin and its significance, SW China," Petroleum Exploration and Development, vol. 42, no. 3, pp. 283-293, 2015.

[34] H. J. Yan, A. L. Jia, G. Ji et al., "Gas-water distribution characteristic of the karst weathering crust type water-bearing gas reservoirs and its development countermeasures: case study of Lower Paleozoic gas reservoir in Gaoqiao, Ordos Basin," Natural Gas Geoscience, vol. 28, no. 5, pp. 801-811, 2017.

[35] Y. Li, S. Qin, Y. Wang, G. Holland, and Z. Zhou, "Tracing interaction between hydrocarbon and groundwater systems with isotope signatures preserved in the Anyue gas field, central Sichuan Basin, China," Geochimica et Cosmochimica Acta, vol. 274, pp. 261-285, 2020.

[36] X. Wang, H. Tian, X. Xiao et al., "Methane-dominated gaseous inclusions in the Sinian carbonate reservoirs in central Sichuan Basin and their implications for natural gas accumulation," Marine and Petroleum Geology, vol. 125, p. 104871, 2021.

[37] Y. Tang, Z. Chen, B. R. Simoneit et al., "Recognition of in situ oil cracking in the Precambrian-Lower cambrian petroleum 
systems of Sichuan basin, southwestern China," Marine and Petroleum Geology, vol. 126, p. 104942, 2021.

[38] S. Laixi, L. Yun, and C. Mingqiang, "Study on Jingbian gas reservoir production characteristics and technical counter measures for depletion during middle and later developing phase," Natural Gas Industry, vol. 26, no. 7, pp. 82-84, 2006.

[39] J. A. Lihua and G. J. Haijun, “The evaluation and recoverability analysis of low-quality reserves in Jingbian gas field," Acta Petrolei Sinica, vol. 33, no. S2, pp. 160-165, 2012.

[40] H. F. Han, Y. Sang, and J. Yang, "Experimental study and application of stimulation technologies for Sinian Dengying Formation reservoirs in the Sichuan Basin," Natural Gas Industry, vol. 36, no. 1, pp. 81-88, 2016.

[41] W. Guoqi, S. Ping, J. Zhang, J. I. Guihao, X. I. Wuren, and X. I. Zengye, "Formation conditions and exploration prospects of Sinian large gas fields, Sichuan Basin," Petroleum Exploration and Development, vol. 40, no. 2, pp. 129-138, 2013. 